\title{
Tubular Cytoplasmic Expression of Zinc Finger Protein SNAI1 in Renal Transplant Biopsies
}

\section{A Sign of Diseased Epithelial Phenotype?}

\author{
Marco Prunotto, ${ }^{\star}$ Lyubov Chaykovska, ${ }^{\dagger}$ Massimo Bongiovanni, ${ }^{\ddagger}$ Milo Frattini, ${ }^{\S}$ Thomas Cagarelli, ${ }^{\ddagger}$ Franziska Weibel, ${ }^{*}$ \\ Maurizio Bruschi, "Antonio Garcia de Herreros, " and Solange Moll ${ }^{\ddagger * *}$
}

\begin{abstract}
From Discovery Technologies, * Roche Innovation Center Basel, Roche Pharma Research and Early Development, Basel, Switzerland; the Clinics for Cardiovascular Surgery, ${ }^{\dagger}$ Zurich University Hospital, Zurich, Switzerland; the Division of Clinical Pathology, ${ }^{\ddagger}$ Department of Pathology and Immunology, University Hospital Geneva, Geneva, Switzerland; the Institute of Pathology, ${ }^{\S}$ Locarno, Switzerland; the Laboratory of Uremia Pathophysiology, "Giannina Gaslini Hospital, Genova, Italy; the Hospital del Mar Medical Research Institute," Barcelona Biomedical Research Park, Barcelona, Spain; and the Institute of Clinical Pathology, ** University Hospital Lausanne, Lausanne, Switzerland
\end{abstract}

Accepted for publication September 12, 2016.

Address correspondence to Marco Prunotto, Ph.D., Roche Innovation Center Basel, Grenzacherstrasse 124, 4070 Basel, Switzerland. E-mail: marco.prunotto@roche.com.

\begin{abstract}
The aim of the present study was to analyze in vivo the role of zinc finger protein SNAI1 (SNAI1) on renal fibrosis. Unilateral ureteral obstruction injury was induced in Snai1 knockout mice. Snai1 gene deletion was, however, only partial and could therefore not be correlated to reduced fibrosis. Expression of SNAI1 protein and epithelial-mesenchymal transformation markers was then assessed in human chronic allograft nephropathy biopsy specimens. Significant up-regulation of SNAI1 protein was detected within cytoplasm of proximal tubules localized, for some of them, near foci of fibrosis and tubular atrophy. No concomitant epithelial-mesenchymal transformation could, however, be demonstrated analyzing the expression of the fibroblast markers vimentin, $\alpha$-smooth muscle actin, and S100A4. SNAI1 cytoplasmic up-regulation was particularly evident in biopsy specimens obtained from calcineurin inhibitor-treated patients, which might be because of, as suggested by in vitro experiments, a decrease of the proteasome chimotrypsin activity. Deeper analysis on chronic allograft nephropathy biopsy specimens suggested that SNAI1 cytoplasmic up-regulation was preceded by a transient increase of phosphorylated heat shock protein 27, p38 mitogenactivated protein kinase, and glycogen synthase kinase $3 \beta$. Concomitant down-regulation of the polyubuquitinylated conjugates was detected in SNAI1 ${ }^{+}$tubules. Altogether, these results might suggest that calcineurin inhibitor-induced tubular SNAI1 protein cytoplasmic accumulation, possibly because of impaired SNAI1 proteasomal degradation and nuclear translocation, might be a sign of a diseased profibrotic epithelial phenotype. (Am J Pathol 2017, 187: 55-69; http://dx.doi.org/10.1016/j.ajpath.2016.09.017)
\end{abstract}

Chronic kidney disease is caused by a wide range of diseases, with diabetes mellitus, hypertension, and primary glomerulopathies being the most common causes in the Western world. ${ }^{1}$ Chronic kidney disease, independent of the primary cause, leads to progressive, irreversible loss of functional renal parenchyma. Renal pathology in chronic kidney disease is characterized by interstitial fibrosis with excessive deposition of extracellular matrix, failed regeneration of tubular epithelium with tubular atrophy, microvascular rarefaction, and inflammation. In renal transplantation, long-term allograft failure remains a central clinical challenge in contrast to short-term allograft survival, where significant improvements have been accomplished. ${ }^{2-4}$

Although the underlying disease processes are mostly elusive, there is no doubt that extensive interstitial fibrosis and tubular atrophy (IFTA) are the final common histopathological lesions in chronic allograft nephropathy (CAN), as in other causes leading to chronic kidney disease.

\footnotetext{
Supported by the Novartis Foundation for medical-biological research (S.M.).

Disclosures: M.P. and F.W. are employees of Hoffmann-La Roche AG
} Basel. 
Uniquely recognized key players in fibrosis progression are the myofibroblasts. ${ }^{5-7}$ These cells account for tissue remodeling after insult, with enhanced collagen synthesis and increased extracellular matrix degradation through secretion of specific metalloproteinases. The cellular origin and the mechanisms inducing myofibroblast activation remain, however, poorly defined. Some fibroblasts are recruited from circulating bone marrow-derived stem cells, whereas others are acquired via the proliferation of resident renal fibroblasts. ${ }^{8}$ In addition, tubular epithelial cells (TECs) have been proposed to have an active role in the fibrosis progression via epithelial-mesenchymal transformation (EMT). ${ }^{9-12}$ Thus, Iwano et $\mathrm{al}^{13}$ observed that more than a third of interstitial myofibroblasts originated from the mesenchymal transition of TECs in the unilateral ureteral obstruction (UUO) model of kidney fibrosis. Moreover, Rastaldi et $\mathrm{al}^{14}$ suggested that TECs could produce extracellular matrix proteins through their previous transition to a mesenchymal phenotype in human glomerular diseases associated with interstitial fibrosis. However, recent data indicate that renal fibrosis could occur in the absence of this cellular transdifferentiation process. ${ }^{15,16}$

EMT is credited to initiate ${ }^{17,18}$ through the induction by transforming growth factor- $\beta$ (TGF- $\beta$ ) of downstream mediators, including the zinc-finger transcription factor zinc finger protein SNAI1 (SNAI1), with consequent deactivation of gene products that act maintaining the epithelial phenotype (ie, the specific epithelial adhesion molecules Ecadherins), TEC depolarization, and activation of a mesenchymal-like gene expression program with transcriptional activation (and derepression) of genes required to sustain mesenchymal-type structures and functions [ie, de novo expression of the fibroblast-specific proteins vimentin, $\alpha$-smooth muscle actin ( $\alpha$-SMA), and S100A $4^{19}$ ]. Consistent with the important role of SNAI1 in TGF- $\beta$-dependent signaling, in vitro SNAI1 overexpression in epithelial cells was demonstrated to promote EMT: in Madin-Darby canine kidney (MDCK) cells, SNAI1 induces an up-regulation of matrix metalloproteinase- 9 transcription driven by a mechanism dependent on the mitogen-activated protein kinase (MAPK) and phosphoinositide 3-kinase signaling pathways. ${ }^{20}$ Different in vitro reports have demonstrated that SNAI1 overexpression represses transcription of many epithelial genes, including E-cadherin and other mucin-1, claudins, and occludins, and promotes morphological changes and reorganization of the actin cytoskeleton. ${ }^{21}$ In addition, in vivo experimental studies in transgenic mice demonstrated that Snail activation repressed the tubular epithelial phenotype, through a downmodulation of E-cadherin, and induced renal fibrosis, with concomitant expression of vimentin, $\alpha$-SMA, and collagen I. ${ }^{21}$ Therefore, inhibiting Snail activity could provide a specific way to prevent or reverse renal fibrosis.

To test this hypothesis, we subjected Snail knockout (KO) mice to UUO injury. Snail gene deletion was, however, only partial, with a $60 \%$ Snail knockdown and a residual $40 \%$ Snai1 expression, and could therefore not be correlated to reduced fibrosis.

We then analyzed SNAI1 protein expression on human renal biopsy specimens from transplant patients with CAN. We observed a SNAI1 protein up-regulation in tubules localized near foci of fibrosis; however, this occurred without any sign of EMT. This SNAI1 up-regulation was detected within tubular cytoplasm and was mostly observed in biopsy specimens of patients treated with calcineurin inhibitors (CNIs). Deeper immunohistochemistry analysis using serial sections on biopsy specimens with CNI-induced tubular toxicity suggested that SNAI1 cytoplasmic upregulation was preceded by a transient up-regulation of phosphorylated heat shock protein 27 (HSP27), p38 MAPK, and glycogen synthase kinase $3 \beta$ (GSK-3 $\beta$ ). In contrast, a down-regulation of the polyubuquitinylated conjugates was detected in the SNAI1-positive tubules. Thus, this CNIinduced tubular HSP27, p38 MAPK, and GSK-3 $\beta$ upregulation might trigger SNAI1 protein up-regulation through a proteasomal degradation inhibition and a nuclear export with cytoplasmic localization. Interestingly, this pattern was observed in chronic, but not in acute, tubular CNI-induced toxicity, suggesting that acute lesions do not lead to a fibrosis process. Altogether, these results might suggest that the SNAI1 protein cytoplasmic accumulation observed in tubules of CNI-treated transplant patients could be a sign of a diseased profibrotic epithelial phenotype.

\section{Materials and Methods}

Mice

The generation of a conditional knockdown Snail mouse carrying null ${ }^{22}$ and Snail ${ }^{\text {flox }}$ conditional alleles ${ }^{23}$ has been described. ${ }^{24}$ This mouse also holds a Cre recombinaseestrogen receptor fusion gene under the control of $\alpha$-actin promoter $(\alpha$-actin CreER). Animals $\alpha$-actin-CreER, Snail null $\left(\right.$ Snail $\left.{ }^{-}\right)$, and Snail flox $\left(\right.$Snail $^{\text {Flox/- }}$ ) were used for further analysis. Animals bearing one copy of the wild-type Snail gene $\left(\right.$ Snail $\left.^{\mathrm{Flox} /+}\right)$ were used as controls. Activation of Cre recombinase was induced in 2- to 2.5-month-old animals by three peritoneal injections of tamoxifen $(0.1 \mathrm{mg}$ per $g$ of mouse weight, dissolved in corn oil) at alternative days. The well-known experimental UUO model of tubular injury, followed by renal fibrosis, was applied. UUO was generated by surgical ligation of the left ureter; the right kidney will be used as the normal control kidney. Mice were then sacrificed 7 days after injury. Ten KO mice (4 months old) and 13 wild-type mice (4 months old) were used for this experiment. Serum, urine, and kidneys were immediately collected, frozen (and formalin fixed for the kidneys), and stored at $-80^{\circ} \mathrm{C}$. Mice were housed and regularly followed according to procedures established and approved by the Animal Research Ethical Committee from the Barcelona Biomedical Research Park (Barcelona, Spain). 


\section{Human Renal Biopsy Specimens}

Human renal tissue, fixed in formaldehyde and embedded in paraffin, was selected from the files of the Department of Pathology, University Hospital Geneva (Geneva, Switzerland), and of the Department of Pathology, University Hospital of Parma (Parma, Italy): five control normal renal tissues were obtained from patients with nephrectomy performed for neoplasia, and 21 biopsy specimens were obtained from 11 renal transplant patients. For five transplant patients (Patients 1 to 5), three sequential biopsy specimens were obtained: a reperfusion biopsy $\left(\mathrm{T}_{0}\right)$, an intermediate biopsy performed for renal dysfunction $\left(\mathrm{T}_{\mathrm{RD}}\right.$; mean time after transplantation, 5 months; range, 10 days to 1 year 4 months), and a protocol biopsy $\left(\mathrm{T}_{\mathrm{P}}\right)$ performed at 1 year after transplantation (mean time after transplantation, 13.4 months; range, 4 to 25 months). All these five patients had a CNI (tacrolimus) in their immunosupressive therapy regimen. In addition to these 15 sequential biopsy specimens, six $T_{R D}$ biopsy specimens were analyzed: three $\mathrm{T}_{\mathrm{RD}}$ biopsy specimens were obtained from three transplant patients (Patients 6 to 8; $\mathrm{T}_{\mathrm{RD}}$ mean time after transplantation, 137 months; range, 17 to 307 months) who did not receive any CNI since several months (Patient 6, 5 months without CNI; Patient 7, 34 months without CNI; Patients 8, did never receive CNI). The other three $\mathrm{T}_{\mathrm{RD}}$ biopsy specimens were obtained from three transplant patients with CNI-induced tubular toxicity histopathologically characterized by chronic (Patients $9, \mathrm{~T}_{\mathrm{RD}}$ time after transplantation, 6 months) and/or acute tubular lesions (Patients 10 and 11, $\mathrm{T}_{\mathrm{RD}}$ time after transplantation, 10 days and 4 months, respectively). For all biopsy specimens, standard analysis using light microscopy, immunofluorescence (with anti-Ig A, G, M, and anti-complement C1q, C3, C4d, and C5b-9 antibodies), and electron microscopy were performed. Each patient gave informed consent before enrollment. The institutional ethical committee board approved the clinical protocol.

\section{Morphological and Immunohistochemistry Analysis}

In the animal experiments, mouse kidneys, removed immediately at the time of sacrifice, were fixed in $4 \%$ formaldehyde for paraffin section for both morphological and immunohistochemical analysis. Formaldehyde-fixed, paraffin-embedded tissue sections ( $2 \mu \mathrm{m}$ thick) were stained with hematoxylin and eosin, periodic acid-Schiff, trichrome, and Sirius red for the evaluation of kidney fibrosis and tubular injury. Immunohistochemistry was performed as follows: after antigen retrieval with pressurized heating chamber (DakoCytomation, Glostrup, Denmark), kidney sections (3 $\mu \mathrm{m}$ thick) were incubated with antibody mouse monoclonal anti-human $\alpha$-SMA (1:400; DakoCytomation), rabbit polyclonal antihuman fibronectin (1:500; DakoCytomation), mouse monoclonal anti-human E-cadherin (1:150; BD Biosciences, Franklin Lakes, NJ), rabbit monoclonal anti-human CD3 (1:4; Ventana, Roche, Basel, Switzerland), and rabbit polyclonal anti-rabbit polyclonal anti-ionized calcium-binding adaptor molecule 1 (1:750; Wako Chemicals USA, Richmond, VA) 1 hour at room temperature, followed by 1-hour incubation with the appropriate horseradish peroxidase-conjugated secondary antibody (1:100; Santa Cruz Biotechnology, Dallas, TX) at room temperature. Slides were developed using Sigma Fast diaminobenzidine chromogenic tablets (SigmaAldrich, St. Louis, MO) and then counterstained with Mayer hematoxylin. Stained sections were examined with a Zeiss microscope (Zeiss, Oberkochen, Germany). Immunostaining was quantified by morphometric analysis. A mean of $10 \mathrm{im}-$ ages per section were captured in the cortical area with a Zeiss microscope (objective, $40 \times /$ section/region) coupled to a Zeiss digital camera. Quantifications were performed with MetaMorph software version 7.7 (Molecular Devices, Sunnyvale, CA). Data were calculated as percentages of stained area on total area (for Sirius red staining and for $\alpha$-SMA, fibronectin, and E-cadherin immunohistochemistry) or as a number of positive interstitial cells on total standard area (for CD3 and rabbit polyclonal anti-ionized calcium-binding adaptor molecule 1 immunochemistry).

Immunohistochemistry of the human renal biopsy specimens was performed as follows: after antigen retrieval with pressurized heating chamber (DakoCytomation), sections $(3 \mu \mathrm{m}$ thick) obtained from the 21 formaldehydefixed, paraffin-embedded biopsy specimens were incubated with a monoclonal anti-human SNAI1 antibody ${ }^{25,26}$ at a 1:300 dilution 1 hour at room temperature, followed by a tyramide signal amplification system (CSAII kit; DakoCytomation). In addition, serial sections ( $3 \mu \mathrm{m}$ thick) of each of the 15 biopsy specimens obtained from Patients 1 to 5 were incubated with five different monoclonal antibodies: vimentin (DakoCytomation) at a 1:50 dilution 1 hour at room temperature, $\alpha$-SMA (kindly gifted by Dr. Giulio Gabbiani, Department of Pathology and Immunology, University of Medicine, Geneva, Switzerland) at a 1:300 dilution 1 hour at room temperature, S100A4 (kindly gifted by Dr. Marie Luce Bochaton-Piallat, Department of Pathology and Immunology, University of Medicine, Geneva, Switzerland) at a 1:10 dilution 1 hour at room temperature, E-cadherins (Novocastra, Newcastle, UK) at a 1:20 dilution 1 hour at room temperature, and glucoseregulated protein 78 (Abcam, Cambridge, UK) at a 2 $\mu \mathrm{g} / \mathrm{mL}$ concentration 1 hour at room temperature. The Envision system (DakoCytomation) was used for detection of the signals for these five antibodies. Moreover, serial sections $\left(3 \mu \mathrm{m}\right.$ thick) of each of the four $\mathrm{T}_{\mathrm{RD}}$ biopsy specimens obtained from Patients 1 and 9 with chronic CNI-induced tubular toxicity and Patients 10 and 11 with chronic and/or acute CNI-induced tubular toxicity were incubated with SNAI1 antibody and with five different antibodies: monoclonal antibodies against HSP27 (Abcam) at a 1:50 dilution 1 hour at room temperature, phosphoHSP27 (Cell Signaling Technology, Danvers, MA) at a 1:50 dilution 1 hour at room temperature, p38-phosphoT180-Y182 (Abcam) at a 1:100 dilution 1 hour at room 
temperature, polyubiquitinylated conjugates (Enzo Life Sciences, Lausen, Switzerland) at a 1:10 dilution 1 hour at room temperature, and rabbit polyclonal antibody against GSK3 $\beta$-phospho-S9 (Abcam) at a 1:20 dilution 1 hour at room temperature. The Envision system (DakoCytomation) was used for detection of the signals for these five antibodies. Liquid diaminobenzidine substrate-chromogen system (DakoCytomation) was used for detection, according to manufacturer's instructions. Counterstaining was performed using Mayer hematoxylin. Stained sections were examined with a Zeiss microscope.

\section{RNA Extraction, Reverse Transcription, and Quantitative PCR}

Total RNA was extracted from frozen kidneys using TRIzol reagent (Life Technologies, Carlsbad, CA). To generate cDNA, $1 \mu \mathrm{g}$ of total RNA from each treatment group was placed in individual sterile $0.2 \mathrm{~mL}$ PCR tubes to which $2 \mu \mathrm{L}$ of random primers $(50 \mu \mathrm{mol} / \mathrm{L})$ and $2 \mu \mathrm{L}$ of oligo $\mathrm{d}(\mathrm{T})_{16}$ $(50 \mu \mathrm{mol} / \mathrm{L})$ (Applied Biosystems, Foster City, CA) were added. The volume was brought up to $11.5 \mu \mathrm{L}$ with sterile water. The tubes were inserted into an Eppendorf Mastercycler PCR machine (Eppendorf, Hamburg, Germany). The mixtures were heated at $70^{\circ} \mathrm{C}$ for 5 minutes and then quickly chilled on ice. Subsequently, $4 \mu \mathrm{L}$ of $5 \times$ First Strand Buffer, $2 \mu \mathrm{L}$ of $0.1 \mathrm{mmol} / \mathrm{L}$ dithiothreitol, $1 \mu \mathrm{L}$ of $10 \mathrm{mmol} / \mathrm{L} \mathrm{dNTP}$ mix, $1 \mu \mathrm{L}$ of SuperScript II Reverse Transcriptase (Invitrogen, Carlsbad, CA), and $0.5 \mu \mathrm{L}$ of RNase inhibitor (20 U/ $\mathrm{mL}$ ) (Applied Biosystems) were added to each reaction. The contents were mixed gently by pipetting up and down, and the tubes were replaced into the PCR machine, where they were incubated for 1 hour at $37^{\circ} \mathrm{C}$. The reaction was terminated by heating the mixture at $95^{\circ} \mathrm{C}$ for 5 minutes.

For quantitative real-time PCR, TaqMan assays were used. Briefly, $1 \mu \mathrm{L}$ of the cDNA was amplified with TaqMan Gene Expression MasterMix (Applied Biosystems) and specific FAM-MGB probes, using an initial denaturation step at $95^{\circ} \mathrm{C}$ for 10 minutes, followed by 40 cycles at $95^{\circ} \mathrm{C}$ for 15 seconds and annealing at $59^{\circ} \mathrm{C}$ for 1 minute. Each sample was analyzed for TGF- $\beta 1, \alpha$-actin, fibronectin, collagen $1 \alpha 1$, and SNAI1 expression. The $18 \mathrm{~S}$ housekeeping gene was used as internal control. The relative expression level was calculated with the Livak method $(2[-\Delta \Delta C(T)])^{27}$ and was expressed as a fold change $\pm \mathrm{SD}$. The accuracy was monitored by the analysis of melting curves. Assay IDs of probes were Mm01178820_m1 for TGF- $\beta 1$, Mm00725412_s1 for $\alpha$ actin, Mm01256744_m1 for fibronectin, Mm00801666_g1 for collagen 1 1 1, and Mm03928990_g1 for 18S (all purchased from Applied Biosystems).

\section{In Vitro Experiments}

MDCK $^{28}$ cells stably transfected with SNAIl gene tagged with hemoagglutinin (HA) were propagated in Dulbecco's modified Eagle's medium in the presence of G418
$(0.5 \mathrm{mg} / \mathrm{mL})$ at $37^{\circ} \mathrm{C}$ in $5 \% \mathrm{CO}_{2}$ atmosphere. Experiments were performed in RPMI 1640 medium in the presence of G418.

For proteasome activity, SNAI1-HA MDCK cells were seeded in a 96-well plate at the density of $10^{4}$ cells/well and treated with cyclosporine A (CsA), tacrolimus, rapamycin, and prednisolone at 1,5 , and $10 \mu \mathrm{g} / \mathrm{mL}$ for 24 hours. Control proteasome blockage was obtained by treatment of the SNAII-HA MDCK cells with bortezomib (Velcade; Millenium Pharmaceutical, Cambridge, MA) at $0.01 \mu \mathrm{g} / \mathrm{mL}$ for 24 hours, whereas control cells were treated with vehicle $(0.05 \%$ dimethyl sulfoxide). SucLLVY-AMC fluorescent product (20S Proteasome Assay Kit; Cayman Chemical, Bridgeport, CT) was then measured with a standard microplate reader. Each experiment was done in triplicate.

For Western blot analysis, SNAII-HA MDCK cells were treated with CsA at $10 \mu \mathrm{g} / \mathrm{mL}$ for 24 hours. Control proteasome blockage was obtained by treatment of the cells with bortezomib at $0.01 \mu \mathrm{g} / \mathrm{mL}$ for 24 hours, whereas control cells were treated with vehicle ( $0.05 \%$ dimethyl sulfoxide). At the end of the treatment, cells were harvested and lysated in 300 $\mu \mathrm{L}$ of Laemmli buffer $(62.5 \mathrm{mmol} / \mathrm{L}$ Tris- $\mathrm{HCl}, \mathrm{pH} 6.8,2 \%$ $\mathrm{w} / \mathrm{v}$ SDS, $100 \mathrm{mmol} / \mathrm{L}$ dithioerythritol, $1 \mathrm{mmol} / \mathrm{L}$ EDTA, and protease inhibitors). After incubation on ice for 30 minutes, lysates were boiled for 5 minutes and centrifugated at 15,000 $\times$ $g$ for 20 minutes. For immunoblotting, $30 \mu \mathrm{g}$ of samples was separated in 8 to $16 \%$ gradient gels and blotted onto nitrocellulose membrane. The following antibodies were used for immunoblotting: anti-polyUb (1:1000, monoclonal P4D1; Santa Cruz Biotechnology, Santa Cruz, CA) and a monoclonal anti-human SNAI1 antibody ${ }^{25,26}$ at a 1:30 dilution. For immunoprecipitation, cells were solubilized on ice for 3 hours with $1 \% \mathrm{v} / \mathrm{v} \mathrm{NP}-40$ in phosphate-buffered saline and centrifuged at $10,000 \times g$ for 10 minutes at $4^{\circ} \mathrm{C}$ to remove the insoluble debris. Non-specific bound proteins were removed by preincubation of supernatants $(500 \mu \mathrm{g})$ with $50 \mu \mathrm{L}$ of protein A-Sepharose beads (Sigma-Aldrich) and subsequent gently rotated for 1 hour at $4^{\circ} \mathrm{C}$. Precleared supernatants were incubated with $3 \mu \mathrm{g}$ of monoclonal anti-HA (clone HA-7; Sigma-Aldrich) overnight at $4^{\circ} \mathrm{C}$ under rotation. Subsequently, $50 \mu \mathrm{L}$ of protein $\mathrm{A}-$ Sepharose beads was added to the immune complex for 3 hours at $4^{\circ} \mathrm{C}$. The beads were pelleted, washed three times with ice-cold solubilized buffer, resuspended in $50 \mu \mathrm{L}$ of Laemmli buffer, heated to $95^{\circ} \mathrm{C}$ for 5 minutes, loaded in 8 to $16 \%$ SDS-PAGE, and transferred to nitrocellulose membrane. Protein bands were visualized by using a VersaDoc 4000 (Bio-Rad, Hercules, CA) apparatus, and QuantityOne software version 4.5 (Bio-Rad) was used to quantify protein band volumes.

\section{Statistical Analysis}

Statistical analysis was performed with SigmaStat software version 3.5 (Systat Software, San Jose, CA). Data were expressed as means \pm SEM. Paired groups were compared 
using either $t$-test or Mann-Whitney rank sum test if normality test failed. Multiple groups were compared using one-way analysis of variance, followed by post hoc Bonferroni $t$-tests. $P \leq 0.05$ was considered statistically significant.

\section{Results}

\section{Partial Loss of Snai1 Does Not Correlate to Reduced Fibrosis in Mice Ligated Kidneys}

Snail KO mice were generated by activation of a ubiquitously expressed Cre recombinase. These animals were subjected to the UUO procedure. Mice at 10 days of Snail Cre recombinase showed a residual $40 \%$ Snail expression measured by quantitative RT-PCR (Figure 1A). On average, renal histology of Snail KO mice was characterized by tubulointerstitial lesions similar to those observed in wild-type mice with tubular injury (lumen dilation with intraluminal debris and flattened tubular epithelial cells), interstitial fibrosis, and interstitial inflammation (Figure 1B). Particularly, no difference in the average degree of fibrosis was detected in $\mathrm{KO}$ mice in comparison with wild-type mice using Sirius red staining with quantitative morphometric analysis (Figure 1C). These morphological results were confirmed by immunohistochemistry coupled with quantitative morphometry analysis (Figure 1C) and by mRNA expression of fibrotic markers (Supplemental Figure S1). Therefore, partial loss of Snail (ie, 60\%) did not correlate to reduced fibrosis in mice ligated kidneys.

Closer analysis of the individual animal Snai1 mRNA expression level variability (Supplemental Figure S2) prompted us to test a correlation between Snai1 mRNA expression with all measured immunohistochemical variables. A weak positive correlation could be observed between expression levels of Snail mRNA and measured immunohistochemical fibrotic markers $\alpha$-SMA and fibronectin $(r=0.704$ and $r=0.809$, respectively $)$ (Supplemental Figure S3, A and B) and a negative one for Ecadherin, with moderate correlation coefficient $(r=-0.321)$ (Supplemental Figure S3C). These results are, in any case, not conclusive because most of the data clustered at one end of the correlation range. No correlation with Snai1 mRNA
B

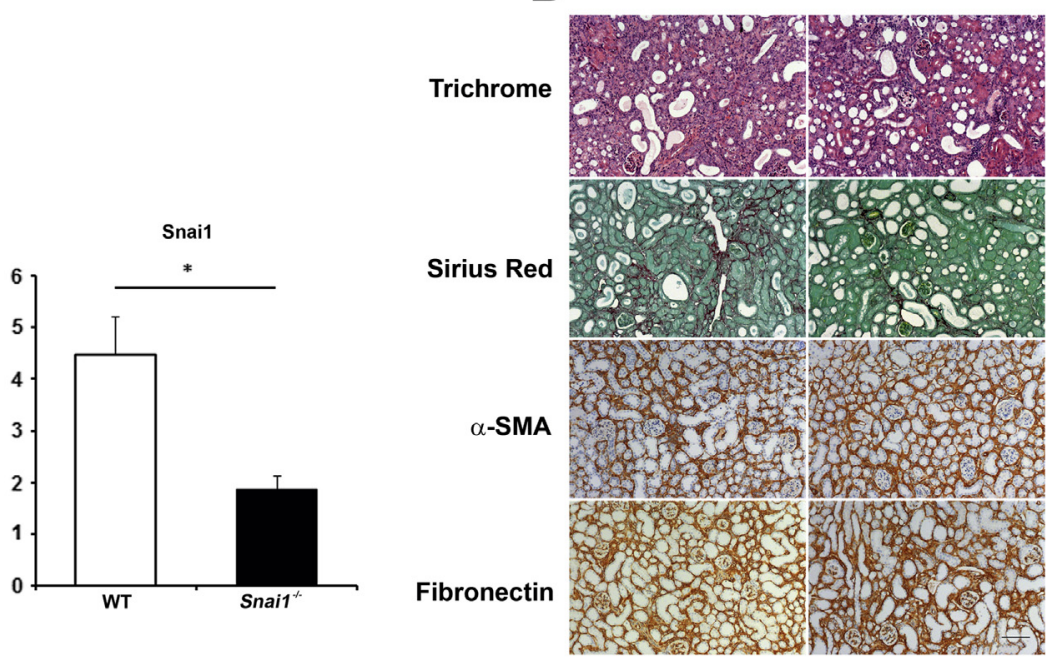

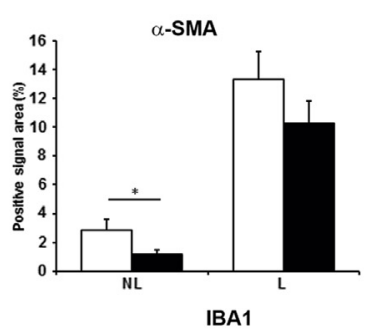
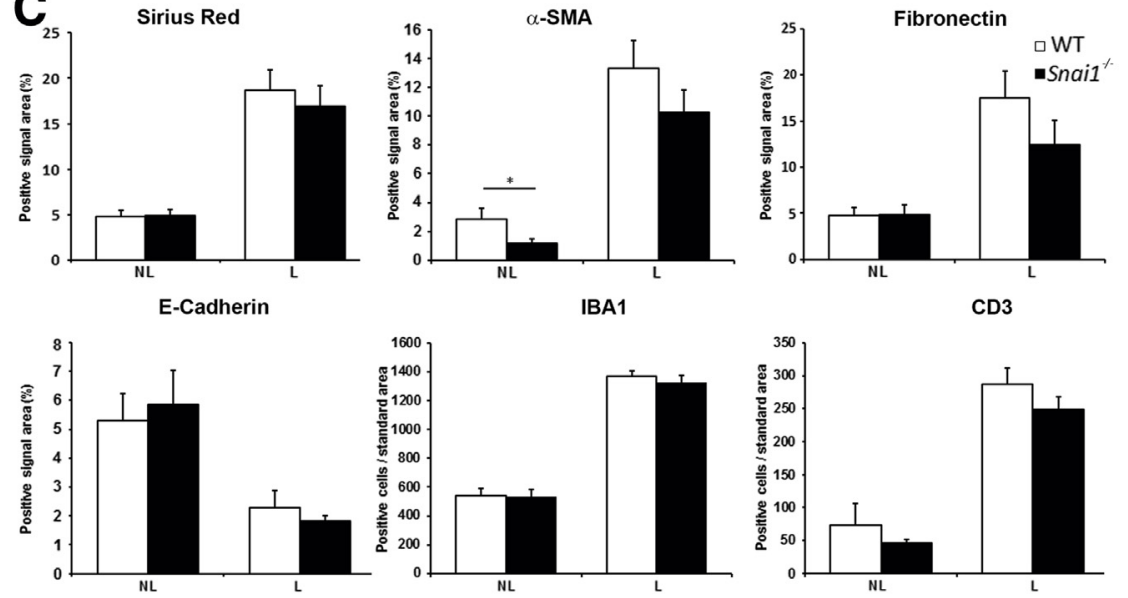

Figure 1 Unilateral ureteral obstruction (UU0)induced renal fibrosis in Snai1 knockout (KO) mice. A: Snai1 mRNA levels in wild-type (WT) and Snai1 conditional KO mice. Snai1 mRNA levels determined by quantitative RT-PCR in obstructed kidneys from WT and Snai1 conditional KO mice $\left(\right.$ Snai1 $\left.^{-1-}\right) 7$ days after UU0. B: Renal histology and immunohistochemistry analyses in WT and Snai1 conditional KO mice. Representative images of similar sections showing hematoxylin and eosin and Sirius red stainings and showing $\alpha$-smooth muscle actin ( $\alpha$-SMA) and fibronectin immunohistochemistry. C: Quantitative morphometric analysis of Sirius red staining and immunochemistry in WT and Snai1 conditional KO mice. Sirius red staining quantification as a percentage of overall cortical fibrosis. $\alpha$-SMA, fibronectin, and E-cadherin immunohistochemistry quantification as a percentage of positive area. IBA1 and CD3 immunohistochemistry quantification as number of positive interstitial cells per total standard area. Data are shown for obstructed $(\mathrm{L})$ and contralateral nonobstructed (NL) kidneys from WT and Snai1 conditional KO mice $\left(\right.$ Snai1 $\left.^{-/}\right)$. Quantitative morphometric analysis of the immunohistochemistry results did not demonstrate statistically significant differences between Snai1 K0 and WT mice in terms of fibrosis ( $\alpha$-SMA and fibronectin), epithelial adhesion molecule marker (E-cadherin), and inflammatory cell infiltration (macrophage IBA1 and lymphocyte (D3). ${ }^{*} P<0.05$. Scale bar $=100 \mu \mathrm{m}$ (B). Original magnification, $\times 120$ (B). IBA1, rabbit polyclonal anti-ionized calcium-binding adaptor molecule 1. 
expression level was observed in the case of measured immunohistochemical inflammation markers $\mathrm{CD} 3$ and rabbit polyclonal anti-ionized calcium-binding adaptor molecule 1 (Supplemental Figure S4). Interestingly, no correlation at all was observed between mRNA expression level of Snai1 and mRNA of all considered markers (data not shown).

\section{SNAI1 Protein Is Detected in the Cytoplasm of Tubules in Human Biopsy Specimens with CAN but Is Not Associated with EMT}

We then analyzed expression and localization of SNAI1 protein in human renal biopsy specimens from transplant patients. We first analyzed protocol biopsy specimens $\left(T_{P}\right)$ obtained from five renal transplant patients with CAN. These $T_{P}$, performed at 1 year after transplantation (mean time after transplantation, 13.4 months; range, 4 to 25 months), were histopathologically characterized by mild to moderate IFTA (grade I to II, according to the Banff classification). ${ }^{29}$ Clinical, biological, and histological data of these five patients (Patients 1 to 5) are detailed in Table 1. A marked tubular increase of the SNAI1 immunostaining was observed, in strong contrast with the weak SNAI1 expression detected in normal control renal tissue (Figure 2A). This up-regulated tubular SNAI1 expression, detected only in some tubular sections, most likely proximal tubules, was localized within cytoplasm as a granular pattern, in strong contrast with the weak and sparse nuclear SNAI1 staining observed in normal kidney. SNAI1 activity requires its presence in the nucleus. ${ }^{30}$ Interestingly, some of these SNAI1 ${ }^{+}$cytoplasmic proximal tubules were directly adjacent to IFTA strips, as demonstrated with the trichrome staining (Figure 2B). To study if this SNAI1 up-regulation was concomitant with EMT, we analyzed expression of four EMT biological markers: vimentin, $\alpha$-SMA, S100A4, and E-cadherin. We could demonstrate, using serial kidney sections, that SNAI1 ${ }^{+}$cytoplasmic tubules, in particular those directly adjacent to the IFTA strips, were clearly negative for the three fibroblast proteins vimentin, $\alpha$-SMA, and S100A4 (Figure 2B). In contrast, and as expected, these three fibroblast markers were detected in the IFTA strips: Vimentin was observed in both atrophic tubules and interstitial fibrotic space, $\alpha$-SMA in interstitial fibrosis, and S100A4 in sparse cells, likely macrophages, as previously described. ${ }^{31} \mathrm{SNAI}^{+}$cytoplasmic tubules were also negative for the specific epithelial adhesion molecule E-cadherin. Finally, a slight increased expression of the glucose-regulated protein 78, a CsA)-induced endoplasmic reticulum stress marker and a key regulator of the unfolded protein response, ${ }^{32}$ was observed in tubules; however, it was not specifically confined to the $\mathrm{SNAI1}^{+}$cytoplasmic proximal tubules (data not shown).

Table 1 Renal Transplant Patient Data

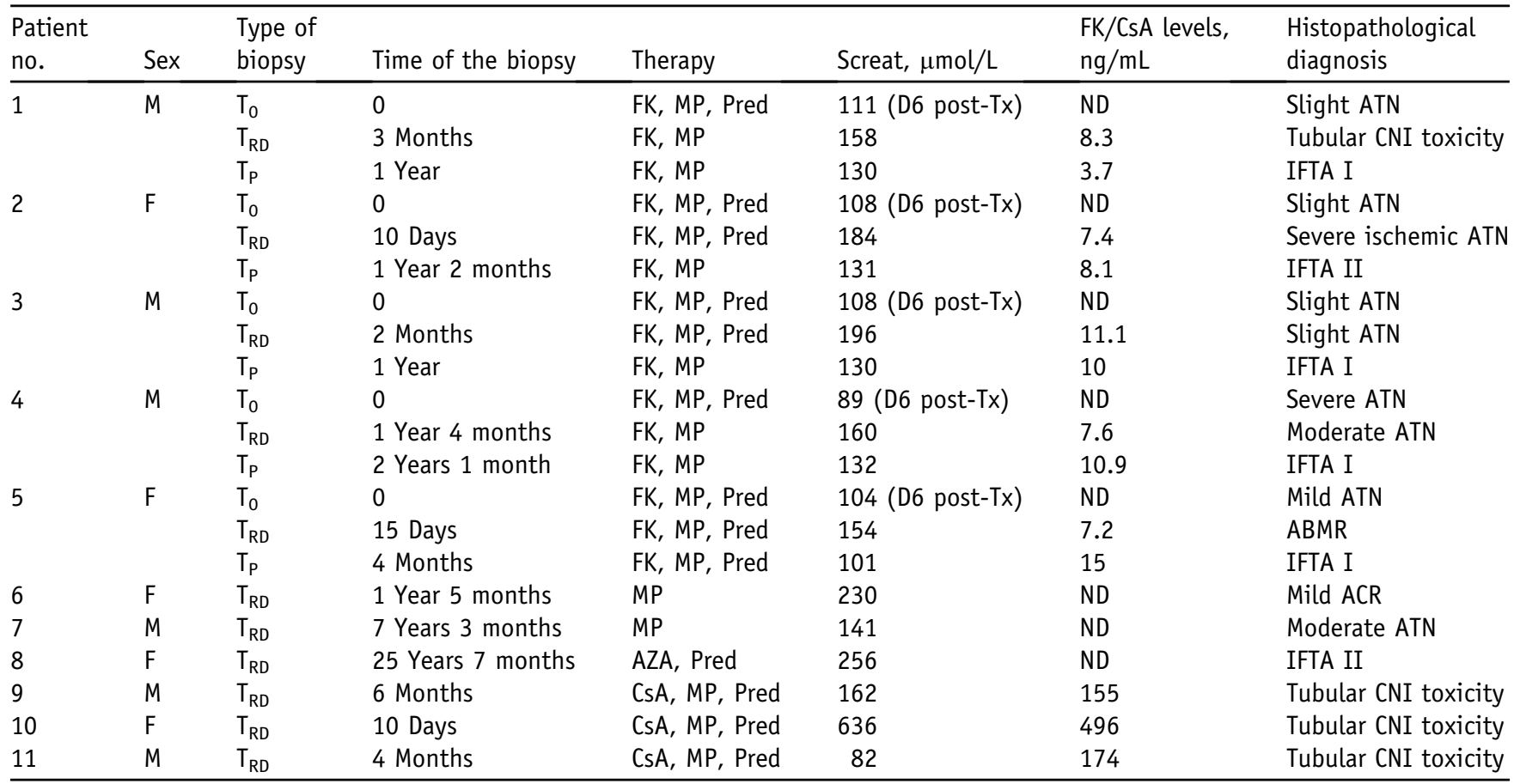

Clinical, biological, and histopathological data of the 11 renal transplant patients (Patients 1 to 11 ).

F, female; M, male; ABMR, antibody-mediated rejection; ACR, acute cellular rejection; ATN, acute tubular necrosis; AZA, azathioprine; CNI, calcineurin inhibitor; CsA, cyclosporine A; D6, day 6; FK, tacrolimus; IFTA, interstitial fibrosis/tubular atrophy (according to the Banff classification); MP, mycophenolate mofetil; ND, not determined; Pred, prednisone; screat, serum creatinine; $T_{0}$, reperfusion biopsy; $T_{P}$, protocol biopsy; $T_{R D}$, biopsy performed for renal dysfunction; Tx, therapy. 


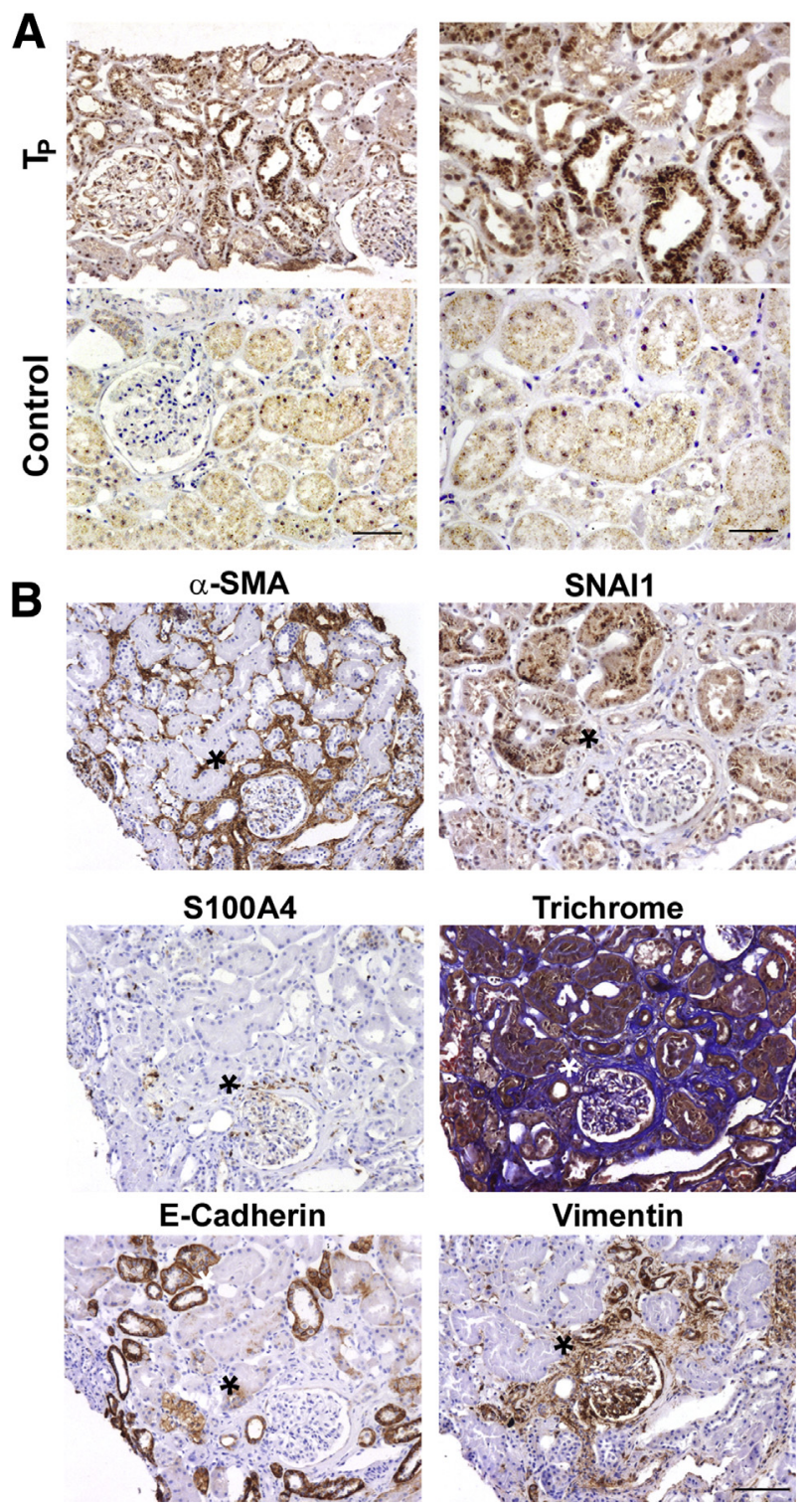

Figure 2 SNAI1 expression in human renal transplant protocol ( $\left.T_{P}\right)$ biopsy specimens from transplant patients with chronic allograft nephropathy (CAN). A: SNAI1 expression and localization in $T_{p}$ biopsy specimens with CAN. Representative images of SNAI1 immunohistochemical analysis of $T_{p}$ biopsy specimens from patients with CAN (Patients 1 to 5 ) and normal control tissues (Control). A marked cytoplasmic increase of the SNAI1 immunostaining is observed in tubules of $T_{p}$ biopsy specimens, most likely proximal tubules, in strong contrast with the weak and sparse nuclear SNAI1 expression in normal control tissues. Tp biopsy obtained from Patient 1 with interstitial fibrosis and tubular atrophy (IFTA) I. B: SNAI1 and epithelial-mesenchymal transformation (EMT) marker expression in $T_{p}$ biopsy specimens with CAN. Serial sections of $T_{P}$ biopsy specimens with IFTA strips. Representative immunostaining of SNAI1 and EMT markers [vimentin, $\alpha$-smooth muscle actin $(\alpha-S M A), S 100 A 4$, and E-cadherin] of $T_{\mathrm{p}}$ biopsy specimens with CAN. SNAI1 ${ }^{+}$ cytoplasmic tubules (asterisks) directly adjacent to IFTA strips, as demonstrated with the trichrome staining, are negative for the three fibroblastspecific proteins vimentin, $\alpha$-SMA, and S100A4, as well as for the specific epithelial adhesion molecule E-cadherin. In IFTA strips, vimentin is observed in both interstitial fibrotic space and atrophic tubules, $\alpha$-SMA in interstitial fibrosis, and S100A4 in sparse interstitial cells, likely macrophages. Transplant protocol biopsy specimen obtained from Patient 1 with IFTA I. Scale bars: $100 \mu \mathrm{m}$ (A, left panels, and $\mathbf{B}) ; 50 \mu \mathrm{m}(\mathbf{A}$, right panels). Original magnifications: $\times 120$ (A, left column); $\times 240$ (A, right column); $\times 100$ (B).
The SNAI1 ${ }^{+}$Protein Cytoplasmic Up-Regulation Observed in Human Transplant Biopsy Specimens Is Induced by CNI

To better understand SNAI1 cytoplasmic up-regulation during renal transplantation, we then analyzed sequential biopsy specimens obtained from the same five transplant patients (Patients 1 to 5) [ie, biopsies performed at reperfusion time ( $\mathrm{T}_{0}$, five biopsies) and intermediate biopsies performed for renal transplant dysfunction $\left(\mathrm{T}_{\mathrm{RD}}\right.$, five biopsies; mean time after transplantation, 5 months; range, 10 days to 1 year 4 months)]. Histopathologically, $\mathrm{T}_{0}$ biopsies were characterized by slight to mild tubular ischemic lesions, and $\mathrm{T}_{\mathrm{RD}}$ biopsies by five different types of lesions (Table 1): tubular CNI-induced toxicity (Patient 1), tubular ischemic-induced lesions (Patient 2), tubular lesions of undetermined origin (CNI or ischemic induced?) but clinically attributed to CNI toxicity (Patients 3 and 4), and acute antibody-mediated rejection (Patient 5). In $\mathrm{T}_{0}$ biopsies, SNAI1 was detected in some rare TPs as a weak and cytoplasmic granular staining (Figure 3). In $\mathrm{T}_{\mathrm{RD}}$ biopsies, different SNAI1 staining patterns could be observed, according to histopathological lesions. In CNIinduced tubular lesions, a marked cytoplasmic granular SNAI1 staining was detected in TPs, similar in localization but stronger in intensity, to the SNAI1 staining observed in $\mathrm{T}_{\mathrm{P}}$ biopsies (Figure 3). In the two biopsies with tubular lesions of undetermined origin but clinically attributed to CNI toxicity, the same marked cytoplasmic granular SNAI1 staining was detected (data not shown). In ischemic-induced tubular lesions, a weak and nuclear SNAI1 staining was detected in some tubules, similar to the control kidney (Figure 3). In acute rejection, a strong and nuclear SNAI1 staining was detected in tubules, similar in localization but stronger in intensity to the control kidney (Figure 3).

Therefore, these results suggest that tubular cytoplasmic SNAI1 up-regulation might be CNI induced. All these five transplant patients received an immunosuppressive regimen, including a CNI (tacrolimus) (Table 1). To confirm that SNAI1 cytoplasmic up-regulation during renal transplantation was related to CNI treatment, three additional $\mathrm{T}_{\mathrm{RD}}$ biopsy specimens obtained from patients without any CNI therapy were analyzed (Patients 6 to 8) (Table 1): one with acute cellular rejection (Patient 6), one with ischemicinduced tubular lesions (Patient 7), and one with chronic allograft lesions with moderate IFTA (Patient 8; IFTA grade II, according to the Banff 2013 classification). ${ }^{29}$ In acute rejection and ischemic-induced tubular lesions, SNAI1 staining was similar in localization (nuclear) and intensity (strong in rejection, weak in ischemic-induced lesions) in patients without CNI therapy than those treated with CNI (data not shown). In case of CAN (Patient 8 with chronic allograft dysfunction treated with azathioprine and prednisone without CNI), a cytoplasmic granular SNAI1 staining was detected in nonatrophic tubules (Figure 3), similar in 
localization but weaker in intensity than $T_{P}$ biopsy specimens (CAN) from CNI-treated patients (Figure $2 \mathrm{~A}$ ) and $\mathrm{T}_{\mathrm{RD}}$ biopsy specimen with CNI-induced tubular lesions (Figure 3).

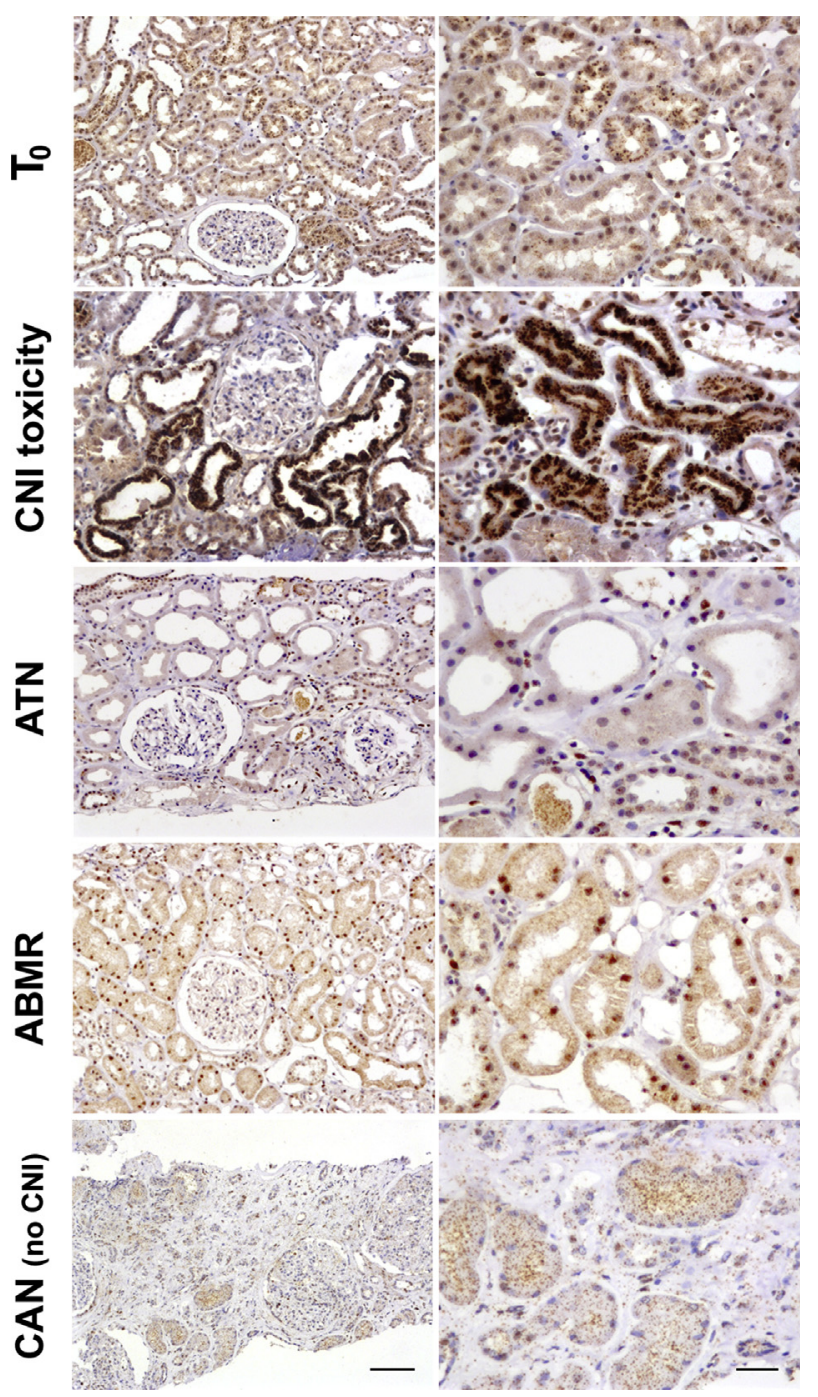

Figure 3 SNAI1 expression in human renal transplant biopsies performed for renal transplant dysfunction $\left(\mathrm{T}_{\mathrm{RD}}\right)$. Representative images of SNAI1 immunohistochemical analysis of sequential renal transplant biopsies performed at reperfusion time $\left(T_{0}\right)$ and for renal transplant dysfunction $\left(T_{R D}\right) . T_{0}$ and intermediate $T_{R D}$ biopsy specimens obtained from five transplant patients (Patients 1 to 5). $\mathrm{T}_{\mathrm{RD}}$ biopsy specimens histopathologically characterized by calcineurin inhibitor (CNI) toxicity (Patient 1), ischemic acute tubular necrosis (Patient 2), acute antibody-mediated rejection (Patient 5), and chronic allograft nephropathy (Patient 8 with no CNI therapy). In $\mathrm{T}_{0}$ biopsy specimens with histopathologically slight signs of acute tubular necrosis (ATN), SNAI1 expression is slightly increased within the cytoplasm of some rare tubules $\left(T_{0}\right.$ Patient 3). In $\mathrm{T}_{\mathrm{RD}}$ biopsy specimens, SNAI1 expression is markedly increased within the cytoplasm of proximal tubules in case of CNI toxicity (CNI toxicity, Patient 1), is not detected in tubular cytoplasm in case of severe ischemic ATN (Patient 2), is increased within the nuclei of tubules but not detected in tubular cytoplasm in case of acute antibody-mediated rejection (ABMR; Patient 5), and is similar to the normal control kidney with a slight cytoplasmic staining in nonatrophic tubules in case of chronic lesions observed in a biopsy specimen from a patient without CNI [chronic allograft nephropathy (CAN), no CNI, Patient 8]. Scale bars: $100 \mu \mathrm{m}$ (left column); $25 \mu \mathrm{m}$ (right column). Original magnifications: $\times 120$ (left column); $\times 240$ (right column).
CNI-Induced SNAI1 Protein Cytoplasmic Up-Regulation Is Associated with an in Vitro Decrease of the Proteasome Chimotrypsin Activity

Therefore, these results, based on sequential $\left(\mathrm{T}_{0}, \mathrm{~T}_{\mathrm{P}}\right.$, and $\mathrm{T}_{\mathrm{RD}}$ ) biopsy specimens obtained from transplant patients treated with CNI, and on $\mathrm{T}_{\mathrm{RD}}$ biopsy specimens obtained from transplant patients without CNI, suggest that tubular cytoplasmic SNAI1 up-regulation might be CNI induced. To test this hypothesis and to analyze the possible pathophysiological mechanism(s) accounting for SNAI1 cytoplasmic accumulation in biopsy specimens from CNI-treated patients, we studied CNI effects on SNAI1 expression in cultured tubular cells, and compared them to those of different immunosuppressive drugs. In light of a previous in vitro study, reporting uncompetitive inhibition of proteasome activity in a CsA-treated murine macrophage cell line, ${ }^{33}$ we hypothesized that SNAI1 cytoplasmic accumulation might be because of a CsA-induced abnormal function of proteasome. It should be reminded that, in eukaryotic cells, the vast majority of the cytosolic and nuclear proteins are degraded via the proteasome-ubiquitin pathway. ${ }^{34,35}$ The $26 \mathrm{~S}$ proteasome, a huge protein degradation machine, contains the 20S proteasome, a proteolytic core complex, and additional subunits, serving to link the proteasome to the ubiquitin pathway, which confers specificity to proteasomal degradation by covalent attachment of (poly)ubiquitin to proteins. The $26 \mathrm{~S}$ proteasome degrades not only abnormal and damaged proteins, such as misfolded or damaged secretory proteins, but also cell cycle regulators, oncogenes, and tumor suppressors, and is implicated in the processing of antigens and in the activation or degradation of transcription factors. The eukaryotic proteasome contains at least five identifiable protease activities, one of them being similar in specificity to chymotrypsin. ${ }^{33}$ Therefore, to address the hypothesis of a cytoplasmic SNAI1 accumulation because of CNI-induced inhibition of the proteasome activity, stable transfected SNAII-HA MDCK cells were treated with CNI (CsA and tacrolimus), rapamycin, and prednisolone, for 24 hours (dose ranging between 1 and $10 \mu \mathrm{g} / \mathrm{mL}$ ), according to the known cellular models of acute CsA toxicity. ${ }^{36}$ Cells treated with a specific proteasome inhibitor (bortezomib, $0.01 \mu \mathrm{g} / \mathrm{mL}$ ), and non-treated cells were used as positive and negative controls, respectively. We used transfected SNAIIHA MDCK cells, because proximal tubular cell lines (human HK-2 cells, pig LLC-PK1 cells, and rat IRPTC cells) did not allow us to obtain any results because of their low endogenous SNAI1 expression, and because SNAII-HA MDCK tool cells were already being generated for other ongoing research projects in the laboratory.

A clear and statistically significant decrease of the proteasome chimotrypsin activity was observed with both CNI CsA and tacrolimus (Figure 4). This CNI-induced decreased proteasome chimotrypsin activity was in strong contrast with the normal activity observed in cells treated with either rapamycin or prednisolone. 


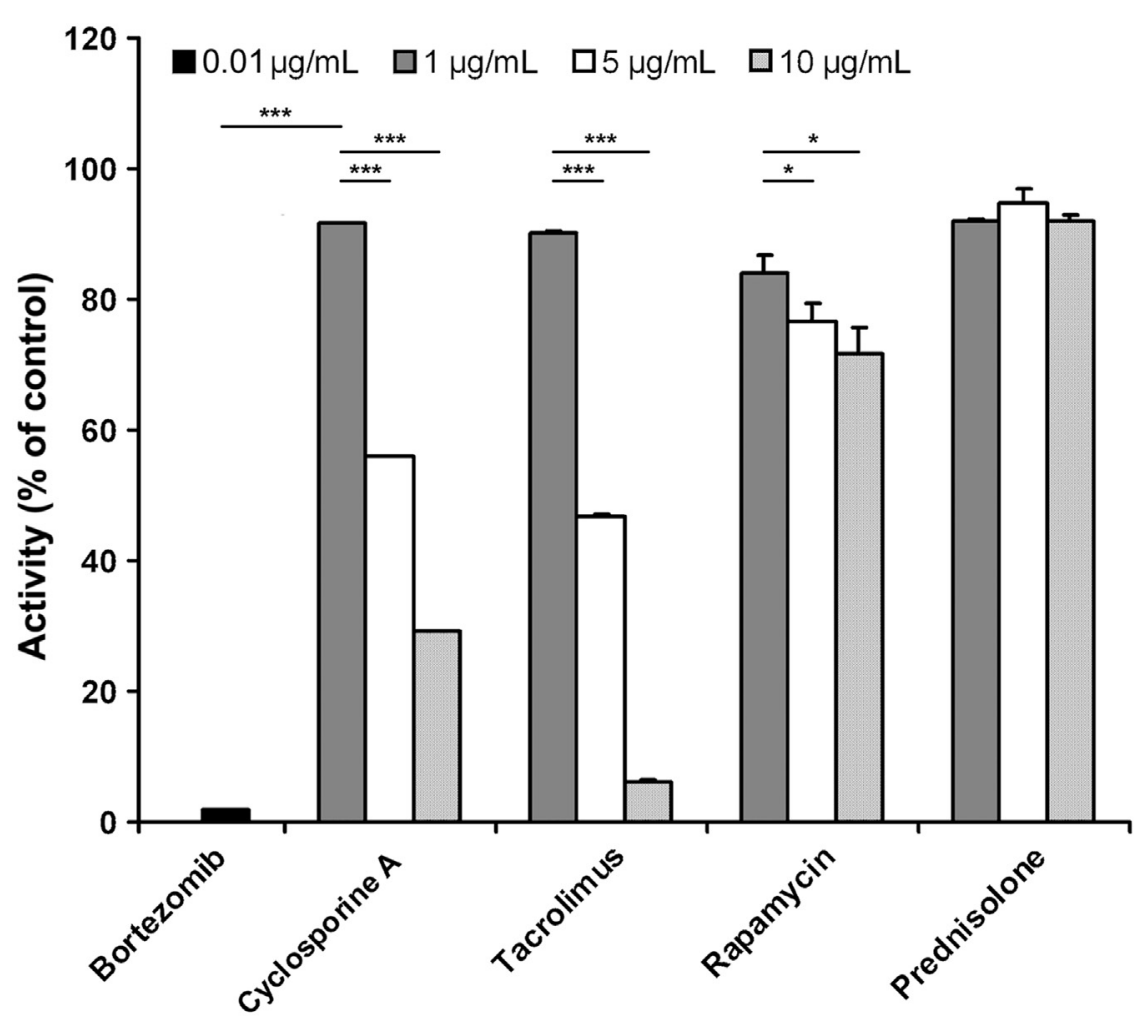

Figure 4 In vitro modulation of proteasome chimotrypsin activity by calcineurin inhibitor (CNI) drugs. Proteasome chimotrypsin activity determined using standard fluorescent substrate method (Suc-LLVY-AMC fluorescent product evaluation) in stable transfected Madin-Darby canine kidney SNAI1-hemoagglutinin cells treated with different immunosuppressive drugs (cyclosporine A, tacrolimus, rapamycin, and prednisolone) and with the specific proteasome inhibitor bortezomid. Proteasome chimotrypsin activity expressed as a percentage of the normal activity determined in control vehicle-treated cells. Each experiment done in triplicate, and cells were treated for 24 hours. A statistically significant reduction of the proteasome chimotrypsin activity is observed in CNI (cyclosporine A and tacrolimus) treated cells. ${ }^{*} P<0.05,{ }^{* * *} P<0.001$.

To attest the SNAI1 protein specificity of the CsA-induced decreased proteasome degradation, we analyzed by Western blot polyubiquinated protein pattern of CsA-treated SNAIIHA MDCK cells using an anti-polyUb antibody. A 30-kDa band, corresponding to the SNAI1 protein molecular weight, was specifically observed in the CsA-treated cells (Figure 5A). This pattern was in strong contrast with the multiple bands observed in the bortezomid-treated cells. Using an anti-SNAI1 antibody, we could demonstrate that the SNAI1-specific $30-\mathrm{kDa}$ band corresponded to the polyubiquinated SNAI1 (Figure 5B). To definitively ensure specificity of polyubiquitination on SNAI1, CsA-treated SNAI1-HA MDCK cells were immunoprecipitated for HA, subsequently blotted, and revealed using an anti-polyUb antibody. The only band specifically detected in CsA-treated cells, but not in the nontreated cells, was the 30-kDa band (data not shown).

Therefore, these in vitro results, demonstrating a CsAinduced polyubiquinated SNAI1 accumulation, although a decreased activity of the proteasome, can be correlated to the in vivo observation of a tubular SNAI1 cytoplasmic accumulation in renal biopsy specimens of CNI-treated patients.

\section{The CNI-Induced SNAI1 Protein Cytoplasmic Up-Regulation Observed in Human Transplant Biopsy Specimens Is Preceded by a Transient Increase of Phosphorylated HSP27, p38 MAPK, and GSK-3 $\beta$}

In light of these in vitro results and to better understand the in vivo pathophysiological events leading to this
CNI-induced SNAI1 protein cytoplasmic up-regulation, we analyzed four $\mathrm{T}_{\mathrm{RD}}$ biopsy specimens obtained from transplant patients with CNI-induced tubular toxicity characterized by chronic (Patients 1 and 9; time after transplantation, 3 and 6 months, respectively) and/or acute lesions (Patients 10 and 11; time after transplantation, 10 days and 4 months, respectively) (Table 1).

Considering previous published studies, ${ }^{30,37-41}$ we hypothesized that CNI-induced SNAI1 protein cytoplasmic up-regulation might be because of a proteasomal degradation inhibition and a nuclear export with cytoplasmic localization. Indeed, CsA was reported to induce a significant up-regulation of HSP27 in proximal tubules of the rat kidney $^{37}$ and to directly hyperphosphorylate HSP27 in monkey renal proximal tubular cells. ${ }^{38}$ On the other hand, HSP27 was demonstrated to be strongly up-regulated during the fibrotic process both in kidney (in the UUO rat model) ${ }^{39}$ and in lung (in different rat pulmonary fibrosis models and in patients with idiopathic pulmonary fibrosis). ${ }^{40}$ Thus, total and phosphorylated HSP27 up-regulation as well as phosphorylated p38 MAPK up-regulation were observed in areas of tubulointerstitial fibrosis in the UUO model. ${ }^{39}$ In addition, HSP27 colocalized with TGF- $\beta 1$ in tubular epithelial cells in $\mathrm{UUO}^{39}$ and with $\alpha$-SMA in the fibrotic areas in the pulmonary rat models. ${ }^{40}$ Furthermore, HSP27 was demonstrated to bind to and stabilize SNAI1 in mesothelial and alveolar epithelial cells, resulting in a protein accumulation and suggesting that HSP27 might induce fibrosis by protecting SNAI1 from its proteasomal degradation. ${ }^{40}$ It should finally be mentioned that phosphorylation ${ }^{30}$ through 


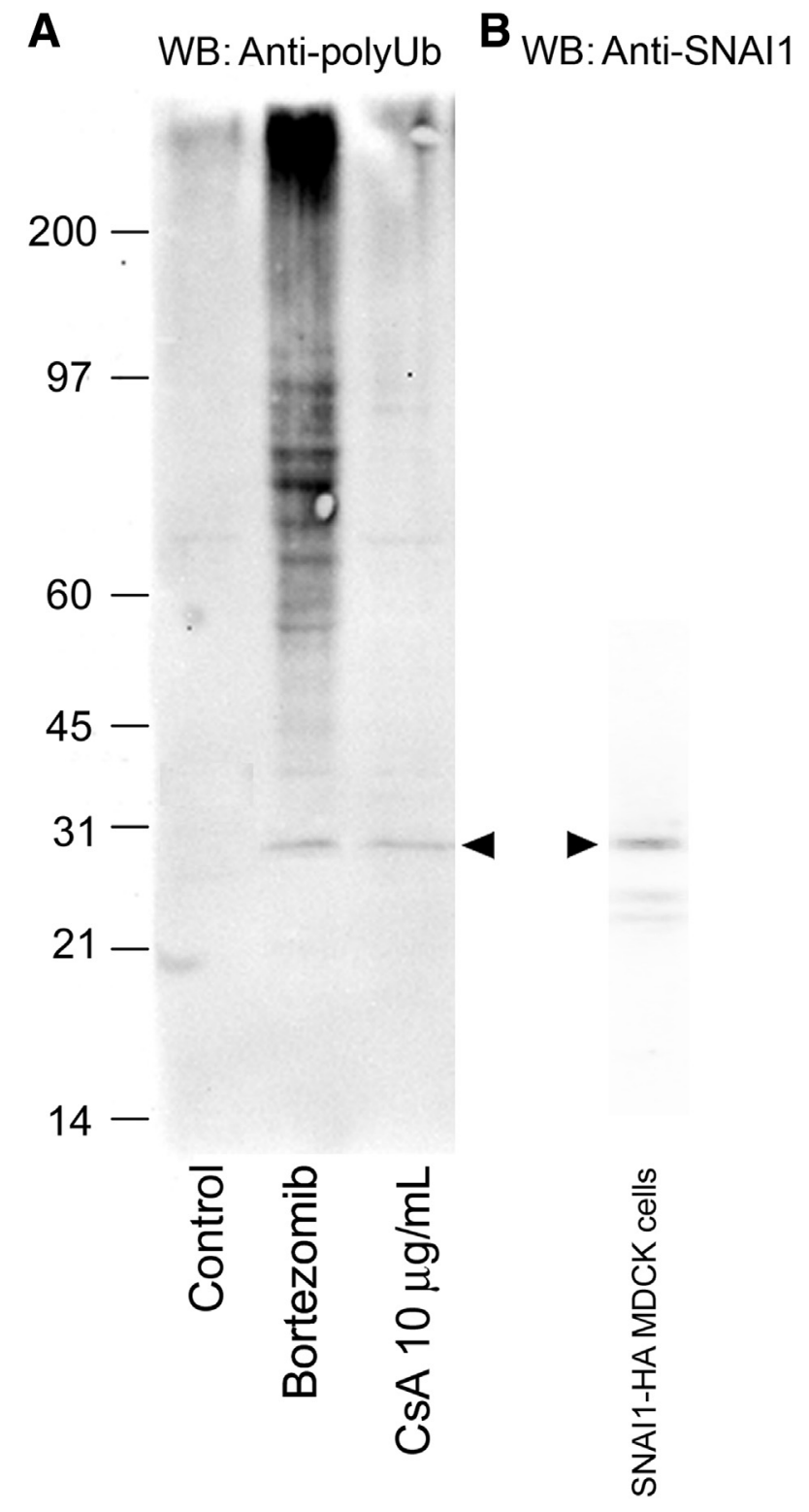

Figure 5 In vitro SNAI1 accumulation because of calcineurin inhibitorreduced proteasome activity. A: Western blot (WB) analysis, using an antipolyUb antibody on SNAI1-hemoagglutinin (HA) stable transfected MadinDarby canine kidney (MDCK) cells [lane 1, non-treated cells; lane 2, bortezomid-treated cells; lane 3, cyclosporine A (CsA)-treated cells]. A unique $30-\mathrm{kDa}$ band (arrowheads), corresponding to the SNAI1 molecular weight, was observed in the CsA-treated cells in comparison to the numerous bands, comprising the $30-\mathrm{kDa}$ band, corresponding to nonspecific polyubiquitinated proteins detected in the bortezomid-treated cells. The $30-\mathrm{kDa}$ band could not be detected in the control non-treated cells. B: Western blot analysis, using an anti-SNAI1 antibody, which recognizes a band at $30 \mathrm{kDa}$ in stable transfected SNAI1-HA MDCK cells.

GSK- $3 \beta^{41}$ was reported to regulate SNAI1 activity as well as its subcellular location. Thus, the SNAI1 protein has two phosphorylation motifs, the first one for protein degradation, which induces SNAI1 ubiquitination and proteolysis, and the second one for subcellular localization, which allows nuclear export and causes SNAI1 to localize in the cytoplasm. $^{30,41}$
Therefore, to address this hypothesis, we analyzed expression and localization of total and phosphorylated HSP27, phosphorylated p38 MAPK, phosphorylated GSK3$\beta$, and polyubiquitinylated conjugates using immunohistochemistry on serial sections of $\mathrm{T}_{\mathrm{RD}}$ biopsy specimens obtained from transplant patients with tubular CNI-induced toxicity. A strong staining of phosphorylated HSP27, p38 MAPK, and GSK-3 $\beta$ was observed in tubules with a SNAI1 nuclear localization (Figure 6A) as well as in tubules with a slight SNAI1 cytoplasmic localization (Figure 6A), but no staining of these proteins could be detected in tubules with the strongest SNAI1 cytoplasmic expression (Figure 6A). In contrast, polyubiquitinylated conjugate staining was downregulated in the SNAI1-positive tubules (Figure 6B and Table 2). Thus, the CNI-induced transient tubular upregulation of HSP27, p38 MAPK, and GSK-3 $\beta$ might trigger SNAI1 cytoplasmic accumulation by protecting it from proteasomal degradation and allowing its nuclear export and localization in the cytoplasm.

This pattern was observed in chronic CNI-induced tubular toxicity histopathologically characterized by tubules localized in areas of interstitial fibrosis but not in acute toxicity. In acute tubular lesions histopathologically characterized by tubular cytoplasmic vacuoles, no SNAI1 staining could be detected in the tubules positive for the three stress-induced proteins (total and phosphorylated HSP27, phosphorylated p38 MAPK, and phosphorylated GSK-3 $\beta$ ) (Figure 7 and Table 2). These results might suggest that acute tubular CNI-induced lesions do not lead to a fibrosis process. Finally, no SNAI1 staining and only slight HSP27, p38 MAPK, and GSK-3 $\beta$ staining could be detected in the normal control kidney biopsy specimen (Supplemental Figure S5).

\section{Discussion}

The pathophysiological role of SNAI1 in the pathogenesis of interstitial fibrosis and EMT is not clearly defined in vivo. SNAI1 up-regulation, triggered by TGF- $\beta$ as demonstrated in vitro in MDCK cells, ${ }^{42}$ is thought to be involved in the renal fibrosis through EMT process activation ${ }^{21,43}$ : i) in reducing tubular epithelial cell adhesion-SNAI1 is a transcriptional repressor of the adherent junction protein E-cadherin, involved in cell-cell adhesion, as well as the tight junction proteins occludin and claudin; ii) in decreasing tubular basement membrane integrity-SNAI1 is a transcriptional inducer of the matrix metalloproteinase-9, as demonstrated in the MDCK epithelial cell line ${ }^{20}$-and thus allowing tubular cells to leave the tubular compartment and migrate into the interstitium; and iii) in reprogramming genes-SNAI1 is a transcriptional inducer of the fibroblast markers vimentin, $\alpha$-SMA, and S100A4-with consequent differentiation of the tubular epithelial cell into the specialized cell type myofibroblast. These findings were observed in vitro, but an increasing number of studies raise 
doubts about SNAI1's role in the EMT process and about the existence of the EMT process in vivo. Thus, in a recent study, activation of the Notch pathway (involving the SNAI1 transcription factors) was shown to induce upregulation of mesenchymal markers in vitro but not in vivo. ${ }^{44}$ In a study using a tamoxifen-inducible Snaill transgenic mouse model that expressed significant levels of the protein in the kidney, an increase in interstitial fibrous collagen was observed, which suggested, but not totally demonstrated, the existence of an EMT. ${ }^{21}$
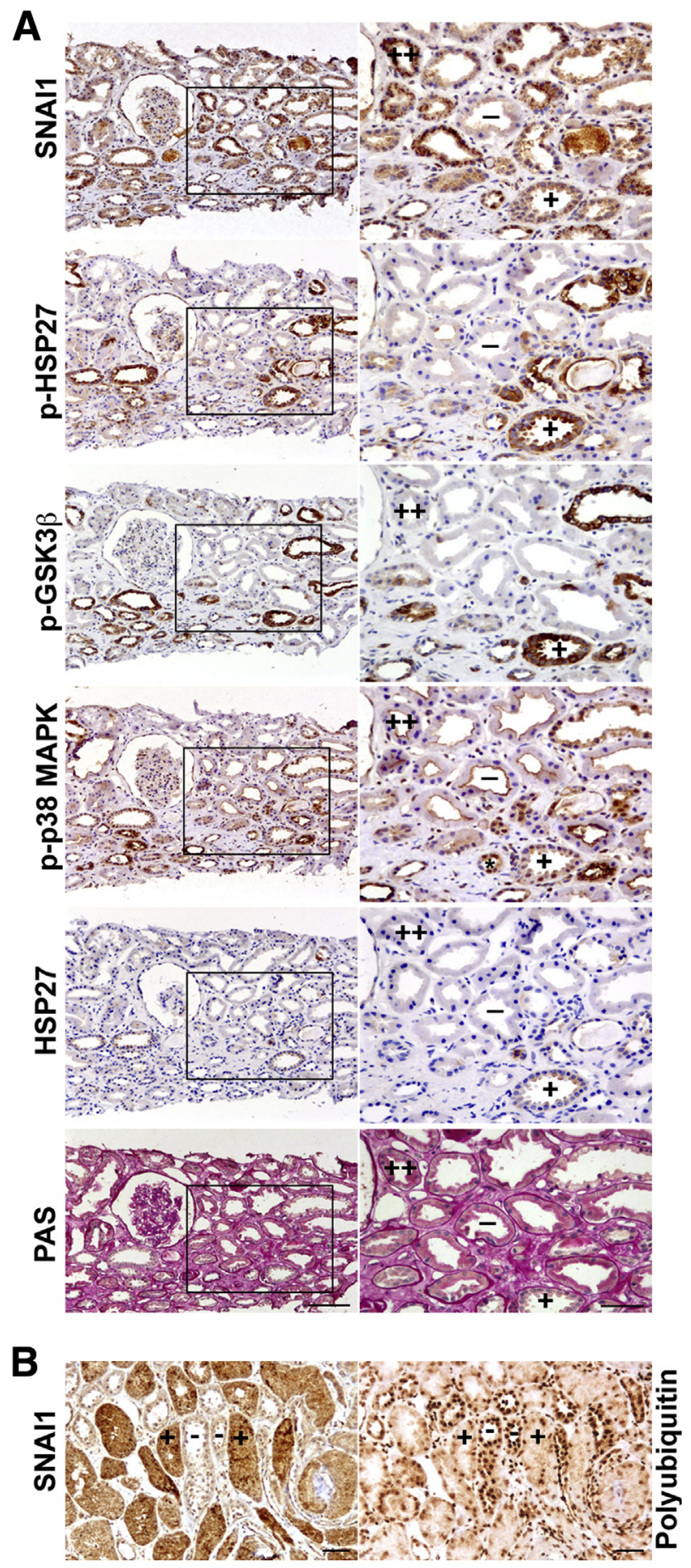

Therefore, to appreciate the possible role of the Snail gene in renal fibrosis and EMT, we generated and used Snail KO mice to circumvent the early embryonic lethality exhibited by Snail $_{\text {dell }} /$ Snail $1_{\text {dell }}$ embryos and permit the study of Snail function later in adult mice. ${ }^{23}$ In this study, we could not clearly demonstrate that decreased levels of Snaill correlate to reduced fibrosis. This was probably because of the partial Snail gene deletion achieved in our experimental model. A trend in that direction seems to be suggested by the correlation between individual animal levels of Snai1 mRNA and measured immunohistochemical fibrotic markers $\alpha$-SMA and fibronectin. These results are, however, far from being conclusive as data clustered mainly at one end of the correlation range.

Very recently and almost contemporary to our work, two seminal articles underlined the role of Snaill in the same obstructive model of renal fibrosis. ${ }^{45,46}$ Grande et $\mathrm{al}^{46}$ showed, through Snaill conditional inactivation in tubular epithelial cells, preserved renal parenchyma in ligated mice and significant reduction in fibrosis burden assessed by Sirius red staining.

The most interesting finding in our study is the SNAI1 protein pattern of expression in renal transplant biopsy specimens. $^{47}$ SNAI1 was demonstrated immunohistochemically to accumulate within the cytoplasm of proximal TECs in protocol biopsy specimens from CNI-treated transplant patients and in diagnostic biopsy specimens characterized by CNI-induced tubular lesions. Despite this SNAI1 protein increase, no evidence of concomitant EMT could be established, as demonstrated in serial immunostained sections by the vimentin, $\alpha$-SMA, and S100A4

Figure 6 SNAI1 expression in human transplant biopsies performed for renal transplant dysfunction $\left(\mathrm{T}_{\mathrm{RD}}\right)$ with calcineurin inhibitor (CNI)-induced chronic toxicity. A: SNAI1 and stress proteins/kinases heat shock protein (HSP) 27, p38 mitogen-activated protein kinase (MAPK), and glycogen synthase kinase $3 \beta$ (GSK-3 $\beta$ ) expression. Serial sections of $T_{R D}$ biopsy specimens histopathologically characterized by CNI-induced chronic toxicity. $T_{R D}$ biopsy specimens obtained from three transplant patients (Patients 1,9, and 11). Representative immunostaining of SNAI1 and stress proteins/kinases: phosphorylated HSP27 (p-HSP27), phosphorylated GSK$3 \beta$ ( $p-G S K-3 \beta)$, phosphorylated p38 MAPK ( $p-p 38$ MAPK), and total HSP27 (HSP27). Periodic acid-Schiff (PAS) staining demonstrating an area of interstitial fibrosis and tubular atrophy. Tubules with positive nuclear SNAI1 staining (asterisk) and slight cytoplasmic SNAI1 staining (plus symbol) are positive for $\mathrm{p}-\mathrm{HSP} 27, \mathrm{p}-\mathrm{GSK}-3 \beta$, and p-p38 MAPK. Tubules with marked positive cytoplasmic SNAI1 staining (double plus symbol) are negative for p-HSP27, p-GSK-3 $\beta$, and p-p38 MAPK. Tubules with negative SNAI1 staining (minus symbol) are negative for p-HSP27, p-GSK-3 $\beta$, and p-p38 MAPK. Boxed areas are shown at higher magnification in the right column. B: SNAI1 and polyubiquitinylated conjugate expression. Serial sections of $T_{R D}$ biopsy specimens with CNI-induced chronic toxicity obtained from three transplant patients (Patients 1, 9, and 11). Representative immunostaining of SNAI1 and polyubiquitinylated conjugates. Tubules with a positive cytoplasmic SNAI1 staining (plus symbols) exhibit a down-regulation of the nuclear polyubiquitinylated conjugate staining, in contrast with the negative SNAI1 tubules (minus symbols) with strong nuclear polyubiquitinylated conjugate staining. Scale bars: $100 \mu \mathrm{m}$ (A, left column); $50 \mu \mathrm{m}$ (A, right column, and $\mathbf{B})$. Original magnifications: $\times 125$ (A, left column); $\times 250$ (A, right column); $\times 160$ (B). 
Table 2 Semiquantitative Evaluation of the Tubular Immunostaining of SNAI1, Stress Proteins/Kinases p-HSP27, p-GSK-3 $\beta$, p-p38 MAPK, Total HSP27, and Polyubiquitinylated Conjugates on Serial Sections of Transplant Human Biopsies $\mathrm{T}_{\mathrm{RD}}$ with Chronic and Acute CNI-Induced Toxicity

\begin{tabular}{|c|c|c|c|c|}
\hline \multirow{2}{*}{$\begin{array}{l}\text { Histopathology } \\
\text { SNAI1 tubular staining }\end{array}$} & \multicolumn{3}{|c|}{ Chronic lesions } & \multirow{2}{*}{$\frac{\text { Acute lesions }}{\text { Negative }}$} \\
\hline & Nuclear & Cytoplasmic + & Cytoplasmic ++ & \\
\hline p-HSP27 & + & + & - & + \\
\hline p-p38 MAPK & + & + & - & + \\
\hline Total HSP27 & + & + & - & + \\
\hline Polyubiquitinated conjugates & + & + & - & ND \\
\hline
\end{tabular}

CNI, calcineurin inhibitor; GSK, glycogen synthase kinase; HSP, heat shock protein; MAPK, mitogen-activated protein kinase; ND, not determined; $\mathrm{p}-$, phosphorylated; $\mathrm{T}_{\mathrm{RD}}$, biopsy performed for renal dysfunction; + , present; ++ , elevated; - , absent.

negative staining of the $\mathrm{SNAI}^{+}$proximal TECs. Interestingly, some of these $\mathrm{SNAI}^{+}$proximal tubular sections were localized in close contact with IFTA strips positively stained for the fibroblast-specific markers. Even if present, findings are insufficient to suggest a clear relationship between tubular cytoplasmic accumulation of SNAI1 and fibrosis progression in the surrounding renal interstitium. It is nevertheless puzzling to observe that $\mathrm{SNAI}^{+}$tubules

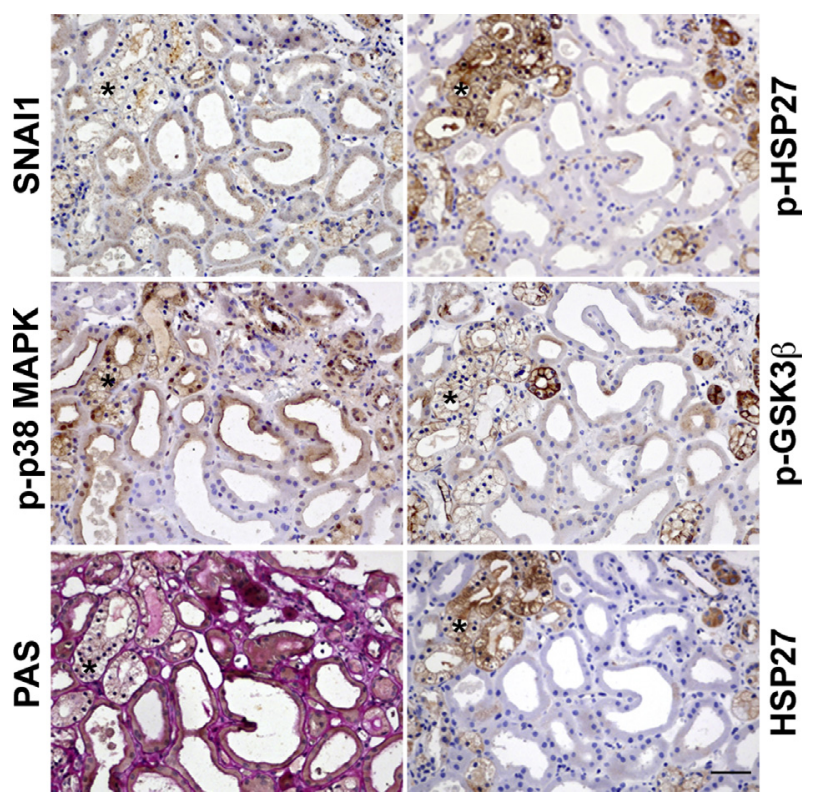

Figure 7 SNAI1 expression in human transplant biopsies performed for renal transplant dysfunction $\left(\mathrm{T}_{\mathrm{RD}}\right)$ with calcineurin inhibitor (CNI)-induced acute tubular toxicity. Serial sections of $T_{R D}$ biopsy specimens histopathologically characterized by CNI-induced acute tubular toxicity. $T_{R D}$ biopsy specimens obtained from three transplant patients (Patients 9, 10, and 11). Representative immunostaining of SNAI1 and stress proteins/kinases: phosphorylated heat shock protein 27 (p-HSP27), phosphorylated glycogen synthase kinase $3 \beta$ ( $p-G S K-3 \beta)$, phosphorylated p38 mitogen-activated protein kinase (p-p38 MAPK), and total HSP27 (HSP27). Periodic acidSchiff (PAS) staining demonstrating acute CNI-induced tubular lesions histopathologically characterized by tubular cytoplasmic vacuoles (asterisks). Tubules with acute CNI-induced lesions are negative for SNAI1 but positive for p-HSP27, p-GSK-3 $\beta$, p-p38 MAPK, and total HSP27. On the upper right side of the sections, an area of interstitial fibrosis and tubular atrophy is observed. Scale bar $=50 \mu \mathrm{m}$. Original magnification, $\times 200$. were observed in patients under CNI treatment, which is known to induce more fibrosis than other drugs, such as rapamycin and methyl prednisolone. ${ }^{48,49}$

As a transcriptional factor, SNAI1 function requires its presence in the nucleus. The SNAI1 cytoplasmic accumulation could be explained, on the one hand, by a CNIinduced inhibition of the proteasome activity and, on the other hand, by a nuclear translocation. Indeed, a statistically significant decrease of the proteasome chimotrypsin activity was observed with both CNI CsA and tacrolimus in our in vitro studies, and a decreased staining of the polyubiquitinylated conjugates was detected in the $\mathrm{SNAI}^{+}$ tubules in our in vivo analyses using immunohistochemistry on serial sections of biopsy specimens with CNI-induced tubular toxicity. In addition, we could demonstrate an upregulation of the phosphorylated HSP27, p38 MAPK, and GSK-3 $\beta$ proteins in the SNAI1 ${ }^{+}$tubules. This up-regulation was transient and preceded the cytoplasmic localization of SNAI1. Interestingly, this pattern was observed only in chronic tubular lesions and not in acute ones. Taken together, these results, which are concordant with previous published studies, might reflect the molecular events involved in the CNI-induced nephrotoxicity leading to renal fibrosis. Thus, we might hypothesize that CNI-induced stress proteins/kinases HSP27/p38 MAPK $^{37,38}$ and/or GSK-3 $\beta$ trigger SNAI1 protein up-regulation through a proteasomal degradation inhibition ${ }^{40}$ and a nuclear export with cytoplasmic localization, ${ }^{41,50}$ with consecutive interstitial fibrosis. $^{40,51}$

This study is the first, to our knowledge, to report SNAI1 induction in human kidneys exposed to cyclosporine. Indeed, $\mathrm{Xu}$-Dubois et $\mathrm{al}^{52}$ analyzed renal graft biopsies performed for routine surveillance or for delayed or declining graft function and demonstrated an association between tubular epithelial phenotypic changes (de novo expression of vimentin and intracellular translocation of $\beta$-catenin) and the production of profibrotic molecules (connective tissue growth factor, HSP47, and laminin). In another study, the same authors showed a nuclear accumulation of SNAI1 and phosphosmad2/3 in tubular cells displaying EMT (intracytoplasmic translocation of $\beta$-catenin and de novo expression of vimentin) and demonstrated an association with graft histological 
lesions (Banff scores), graft dysfunction, and proteinuria. ${ }^{53}$ However, they did not analyze if there was a correlation with the CNI treatment. Galichon et $\mathrm{al}^{54}$ analyzed rat kidneys exposed to cyclosporine and demonstrated a SNAI1 induction at the mRNA level. However, these authors did not analyze SNAI1 expression at the protein level. Our results are concordant with the recent published study by Koesters et al. ${ }^{55}$ These authors demonstrated that in vivo TGF- $\beta_{1}$ overexpression in renal tubules did not induce a complete EMT, as determined analyzing S100A4 expression. In contrast, and similarly to our observation that $\mathrm{SNAI}^{+}$tubules were directly adjacent to interstitial fibrosis, they showed that TGF- $\beta_{1}$ tubular overexpression induced a mild to moderate diffuse fibrosis associated with interstitial proliferation characterized by increased local fibroblasts, $\alpha$-SMA-positive myofibroblasts, and few irregularly distributed S100A4positive interstitial cells. Therefore, the present study joins those that did not find evidence for a contribution of EMT to renal fibrosis. ${ }^{16,55-58}$ Interestingly, fate mapping of renal epithelial cells within the work of Grande et $\mathrm{al}^{46}$ could not detect any sign of a full EMT program that delivers transformed epithelial cells to the interstitium either.

Also, in the same study, Koesters et $\mathrm{al}^{55}$ observed tubular autophagy in the late stages of the disease, leading to tubular degeneration. Moreover, in another study, Pallet et al ${ }^{59}$ showed that CsA activated autophagy in primary cultured human renal tubular cells as well as in injured (vacuolated and necrotic) tubules of CsA-treated rats. As known in recent years, autophagy represents another mechanism of programed cell death-in addition to apoptosis. ${ }^{60,61}$ The autophagy type of programed cell death might underlie tubular degeneration, which is associated with interstitial fibrosis. As CsA directly up-regulates TGF- $\beta 1$ expression in tubular epithelial cells independently of the hemodynamic effects of the renin-angiotensin system in chronic calcineurin inhibitor nephrotoxicity, ${ }^{62,63}$ it might be postulated that CsA-induced tubular autophagy could be mediated by TGF- $\beta 1$. Finally, detachment of epithelial cells from the matrix (anoikis) is known to trigger autophagy. ${ }^{64}$ Therefore, when tubular cells lose their intercellular junctional contacts, and also their contacts with the basement membrane, they might lose some of their junctional proteins, such as E-cadherins, because of the autophagy and without expression of transcriptional factors associated with EMT. SNAI1 accumulation might reflect a diseased epithelial phenotype, observed in close contact with interstitial cells initiating fibrosis within the renal graft. It is, in fact, increasingly appreciated that acute tubular injury, such as toxic or ischemic lesions, is a major contributor to kidney fibrosis. Thus, the role of a diseased epithelial phenotype in kidney fibrosis progression as a contributing factor of myofibroblast activation is emerging. Epithelial cell homeostasis seems pivotal in the normal kidney architecture preservation, and particularly in the control of interstitial cell biology. Thus, injured tubular epithelial cells were recently demonstrated to be a major source of proinflammatory cytokines in experimental models of kidney fibrosis. ${ }^{65}$ Proximal tubular cells were shown to be arrested in the $\mathrm{G}_{2} / \mathrm{M}$ stage of the cell cycle after various injuries, such as toxic and ischemic injuries, to produce profibrotic growth factors able to stimulate fibroblast proliferation and collagen synthesis, and to modulate phenotype of the surrounding interstitium. These findings were elegantly confirmed by a series of in vivo mechanistic experiments, by selective epithelial injury, performed by the same group. ${ }^{66}$ On the contrary, healthy, fully differentiated epithelial cells were demonstrated to contribute to the general maintenance of the static state of mesenchymal cells, as shown by Udo et al. ${ }^{67}$ Indeed, these authors demonstrated that differentiated MDCK cells were able to inhibit the regeneration of mesenchymal stem cells originating from co-cultured adipose tissue. Tubular epithelial cells are, therefore, emerging as cells contributing to renal fibrosis in kidney diseases, not through direct physical involvement like in the EMT process, but through directing general maintenance of the static state of the surrounding mesenchymal interstitial cells.

Our observations suggest that SNAI1 cytoplasmic accumulation might be, as shown by in vitro experiments and in vivo analyses, because of a CNI-induced inhibition of proteasome activity and a nuclear export with cytoplasmic localization, and might reflect a diseased epithelial phenotype expression. These findings are concordant to the published studies by Kanarek et $\mathrm{al}^{68}$ and, more recently, by Grande et al. ${ }^{46}$ These authors reported a nuclear Snail upregulation in an in vivo model of mice deficient for the ubiquitin ligase $S C F^{\beta-T r C P}$. In this study, Snail accumulation, which was observed in seminiferous tubules, resulted in a severe testicular phenotype alteration characterized by disordered architecture and spermatogenesis defect. Remarkably, Snail depletion rescued testis normal architecture and function.

In conclusion, we believe that SNAI1 tubular accumulation, if not a direct cause of phenotypical modulation of surrounding interstitium, is a sign of a diseased epithelium. Preservation of epithelial cell integrity or blockade of the progressive alteration of TECs emerges as a pivotal strategy in preserving renal graft function.

\section{Acknowledgments}

We thank Dr. Vincent Braunersreuther for the intellectual input and Agnès Pernin-Chollet for her technical help.

\section{Supplemental Data}

Supplemental material for this article can be found at http://dx.doi.org/10.1016/j.ajpath.2016.09.017.

\section{References}

1. United States Renal Data System: URSD 2010 Annual Data Report, Atlas of Chronic Kidney Disease and End-Stage Renal Disease in the 
United States. Bethesda, MD: National Institutes of Health, National Institute of Diabetes and Digestive and Kidney Diseases, 2010

2. Meier-Kriesche HU, Schold JD, Kaplan B: Long-term renal allograft survival: have we made significant progress or is it time to rethink our analytic and therapeutic strategies? Am J Transplant 2004, 4:1289-1295

3. Nankivell BJ, Chapman JR: Chronic allograft nephropathy: current concepts and future directions. Transplantation 2006, 81:643-654

4. Mengel M: The kidney transplant: new horizons. Curr Opin Nephrol Hypertens 2010, 19:260-265

5. Grande MT, Lopez-Novoa JM: Fibroblast activation and myofibroblast generation in obstructive nephropathy. Nat Rev Nephrol 2009, 5:319-328

6. Hinz B, Phan SH, Thannickal VJ, Galli A, Bochaton-Piallat ML, Gabbiani G: The myofibroblast: one function, multiple origins. Am J Pathol 2007, 170:1807-1816

7. Watsky MA, Weber KT, Sun Y, Postlethwaite A: New insights into the mechanism of fibroblast to myofibroblast transformation and associated pathologies. Int Rev Cell Mol Biol 2010, 282:165-192

8. Burns WC, Thomas MC: The molecular mediators of type 2 epithelial to mesenchymal transition (EMT) and their role in renal pathophysiology. Expert Rev Mol Med 2010, 12:e17

9. Kalluri R, Neilson EG: Epithelial-mesenchymal transition and its implications for fibrosis. J Clin Invest 2003, 112:1776-1784

10. Liu Y: Epithelial to mesenchymal transition in renal fibrogenesis: pathologic significance, molecular mechanism, and therapeutic intervention. J Am Soc Nephrol 2004, 15:1-12

11. Burns WC, Kantharidis P, Thomas MC: The role of tubular epithelialmesenchymal transition in progressive kidney disease. Cells Tissues Organs 2007, 185:222-231

12. Mucsi I, Rosivall L: Epithelial-mesenchymal transition in renal tubular cells in the pathogenesis of progressive tubulo-interstitial fibrosis. Acta Physiol Hung 2007, 94:117-131

13. Iwano M, Plieth D, Danoff TM, Xue C, Okada H, Neilson EG: Evidence that fibroblasts derive from epithelium during tissue fibrosis. J Clin Invest 2002, 110:341-350

14. Rastaldi MP, Ferrario F, Giardino L, Dell'Antonio G, Grillo C, Grillo P, Strutz F, Muller GA, Colasanti G, D’Amico G: Epithelialmesenchymal transition of tubular epithelial cells in human renal biopsies. Kidney Int 2002, 62:137-146

15. Humphreys BD, Valerius MT, Kobayashi A, Mugford JW, Soeung S, Duffield JS, McMahon AP, Bonventre JV: Intrinsic epithelial cells repair the kidney after injury. Cell Stem Cell 2008, 2:284-291

16. Humphreys BD, Lin SL, Kobayashi A, Hudson TE, Nowlin BT, Bonventre JV, Valerius MT, McMahon AP, Duffield JS: Fate tracing reveals the pericyte and not epithelial origin of myofibroblasts in kidney fibrosis. Am J Pathol 2010, 176:85-97

17. Evans AJ, Russell RC, Roche O, Burry TN, Fish JE, Chow VW, Kim WY, Saravanan A, Maynard MA, Gervais ML, Sufan RI, Roberts AM, Wilson LA, Betten M, Vandewalle C, Berx G, Marsden PA, Irwin MS, Teh BT, Jewett MA, Ohh M: VHL promotes E2 box-dependent E-cadherin transcription by HIF-mediated regulation of SIP1 and snail. Mol Cell Biol 2007, 27:157-169

18. Krishnamachary B, Zagzag D, Nagasawa H, Rainey K, Okuyama H, Baek JH, Semenza GL: Hypoxia-inducible factor-1-dependent repression of E-cadherin in von Hippel-Lindau tumor suppressornull renal cell carcinoma mediated by TCF3, ZFHX1A, and ZFHX1B. Cancer Res 2006, 66:2725-2731

19. Guarino M, Tosoni A, Nebuloni M: Direct contribution of epithelium to organ fibrosis: epithelial-mesenchymal transition. Hum Pathol 2009, 40:1365-1376

20. Jorda M, Olmeda D, Vinyals A, Valero E, Cubillo E, Llorens A, Cano A, Fabra A: Upregulation of MMP-9 in MDCK epithelial cell line in response to expression of the Snail transcription factor. J Cell Sci 2005, 118:3371-3385

21. Boutet A, De Frutos CA, Maxwell PH, Mayol MJ, Romero J, Nieto MA: Snail activation disrupts tissue homeostasis and induces fibrosis in the adult kidney. EMBO J 2006, 25:5603-5613
22. Carver EA, Jiang R, Lan Y, Oram KF, Gridley T: The mouse snail gene encodes a key regulator of the epithelial-mesenchymal transition. Mol Cell Biol 2001, 21:8184-8188

23. Murray SA, Carver EA, Gridley T: Generation of a Snail1 (Snai1) conditional null allele. Genesis 2006, 44:7-11

24. Batlle R, Alba-Castellon L, Loubat-Casanovas J, Armenteros E, Franci C, Stanisavljevic J, Banderas R, Martin-Caballero J, Bonilla F, Baulida J, Casal JI, Gridley T, Garcia de Herreros A: Snaill controls TGF-beta responsiveness and differentiation of mesenchymal stem cells. Oncogene 2013, 32:3381-3389

25. Barbera MJ, Puig I, Dominguez D, Julien-Grille S, GuaitaEsteruelas S, Peiro S, Baulida J, Franci C, Dedhar S, Larue L, Garcia de Herreros A: Regulation of Snail transcription during epithelial to mesenchymal transition of tumor cells. Oncogene 2004, 23: $7345-7354$

26. Franci C, Takkunen M, Dave N, Alameda F, Gomez S, Rodriguez R, Escriva M, Montserrat-Sentis B, Baro T, Garrido M, Bonilla F, Virtanen I, Garcia de Herreros A: Expression of Snail protein in tumor-stroma interface. Oncogene 2006, 25:5134-5144

27. Livak KJ, Schmittgen TD: Analysis of relative gene expression data using real-time quantitative PCR and the 2(-Delta Delta C(T)) method. Methods 2001, 25:402-408

28. Herzlinger DA, Easton TG, Ojakian GK: The MDCK epithelial cell line expresses a cell surface antigen of the kidney distal tubule. J Cell Biol 1982, 93:269-277

29. Haas M, Sis B, Racusen LC, Solez K, Glotz D, Colvin RB, Castro MC, David DS, David-Neto E, Bagnasco SM, Cendales LC, Cornell LD, Demetris AJ, Drachenberg CB, Farver CF, Farris AB 3rd, Gibson IW, Kraus E, Liapis H, Loupy A, Nickeleit V, Randhawa P, Rodriguez ER, Rush D, Smith RN, Tan CD, Wallace WD, Mengel M: Banff 2013 meeting report: inclusion of c4d-negative antibody-mediated rejection and antibody-associated arterial lesions. Am J Transplant 2014, 14:272-283

30. Dominguez D, Montserrat-Sentis B, Virgos-Soler A, Guaita S, Grueso J, Porta M, Puig I, Baulida J, Franci C, Garcia de Herreros A: Phosphorylation regulates the subcellular location and activity of the snail transcriptional repressor. Mol Cell Biol 2003, 23:5078-5089

31. Le Hir M, Hegyi I, Cueni-Loffing D, Loffing J, Kaissling B: Characterization of renal interstitial fibroblast-specific protein 1/S100A4positive cells in healthy and inflamed rodent kidneys. Histochem Cell Biol 2005, 123:335-346

32. Paslaru L, Pinto M, Morange M: GRP78 induction by cyclosporin A in human HeLa cells. FEBS Lett 1994, 350:304-308

33. Meyer S, Kohler NG, Joly A: Cyclosporine A is an uncompetitive inhibitor of proteasome activity and prevents NF-kappaB activation. FEBS Lett 1997, 413:354-358

34. Zwickl P, Voges D, Baumeister W: The proteasome: a macromolecular assembly designed for controlled proteolysis. Philos Trans R Soc Lond B Biol Sci 1999, 354:1501-1511

35. Gallastegui N, Groll M: The $26 \mathrm{~S}$ proteasome: assembly and function of a destructive machine. Trends Biochem Sci 2010, 35:634-642

36. Jiang $T$, Acosta D: An in vitro model of cyclosporine-induced nephrotoxicity. Fundam Appl Toxicol 1993, 20:486-495

37. Stacchiotti A, Rezzani R, Angoscini P, Corsetti G, Bianchi R: Distribution of heat shock proteins in kidneys of rats after immunosuppressive treatment with cyclosporine A. Acta Histochem 2001, 103: 167-177

38. Paslaru L, Rallu M, Manuel M, Davidson S, Morange M: Cyclosporin A induces an atypical heat shock response. Biochem Biophys Res Commun 2000, 269:464-469

39. Vidyasagar A, Reese S, Acun Z, Hullett D, Djamali A: HSP27 is involved in the pathogenesis of kidney tubulointerstitial fibrosis. Am J Physiol 2008, 295:F707-F716

40. Wettstein G, Bellaye PS, Kolb M, Hammann A, Crestani B, Soler P, Marchal-Somme J, Hazoume A, Gauldie J, Gunther A, Micheau O, Gleave M, Camus P, Garrido C, Bonniaud P: Inhibition of HSP27 
blocks fibrosis development and EMT features by promoting Snail degradation. FASEB J 2013, 27:1549-1560

41. Yagyu $T$, Monden $T$, Tamaki $Y$, Morimoto $H$, Takeda $T$, Kobayashi T, Shimano T, Murakami H, Mori T: Use of a local immunotherapy as an adjunctive tool for the generation of human monoclonal antibodies from regional lymph nodes of colonic cancer patients. Jpn J Cancer Res 1992, 83:20-23

42. Peinado H, Quintanilla M, Cano A: Transforming growth factor beta1 induces snail transcription factor in epithelial cell lines: mechanisms for epithelial mesenchymal transitions. J Biol Chem 2003, 278: 21113-21123

43. Kudo-Saito C, Shirako H, Takeuchi T, Kawakami Y: Cancer metastasis is accelerated through immunosuppression during Snailinduced EMT of cancer cells. Cancer Cell 2009, 15:195-206

44. Bielesz B, Sirin Y, Si H, Niranjan T, Gruenwald A, Ahn S, Kato H, Pullman J, Gessler M, Haase VH, Susztak K: Epithelial Notch signaling regulates interstitial fibrosis development in the kidneys of mice and humans. J Clin Invest 2010, 120:4040-4054

45. Lovisa S, LeBleu VS, Tampe B, Sugimoto H, Vadnagara K, Carstens JL, Wu CC, Hagos Y, Burckhardt BC, Pentcheva-Hoang T, Nischal H, Allison JP, Zeisberg M, Kalluri R: Epithelial-to-mesenchymal transition induces cell cycle arrest and parenchymal damage in renal fibrosis. Nat Med 2015, 21:998-1009

46. Grande MT, Sanchez-Laorden B, Lopez-Blau C, De Frutos CA, Boutet A, Arevalo M, Rowe RG, Weiss SJ, Lopez-Novoa JM, Nieto MA: Snail1-induced partial epithelial-to-mesenchymal transition drives renal fibrosis in mice and can be targeted to reverse established disease. Nat Med 2015, 21:989-997

47. Vitalone MJ, O’Connell PJ, Jimenez-Vera E, Yuksel A, Wavamunno M, Fung CL, Chapman JR, Nankivell BJ: Epithelial-tomesenchymal transition in early transplant tubulointerstitial damage. $\mathrm{J}$ Am Soc Nephrol 2008, 19:1571-1583

48. Lutz J, Zou H, Liu S, Antus B, Heemann U: Apoptosis and treatment of chronic allograft nephropathy with everolimus. Transplantation 2003, 76:508-515

49. Azzola A, Havryk A, Chhajed P, Hostettler K, Black J, Johnson P, Roth M, Glanville A, Tamm M: Everolimus and mycophenolate mofetil are potent inhibitors of fibroblast proliferation after lung transplantation. Transplantation 2004, 77:275-280

50. Strauss JS: Editorial: antibiotic therapy for acne vulgaris. Arch Dermatol 1975, 111:1563

51. Omenaas E, Gulsvik A, Einbu O, Hestetun PA: A smoking cessation campaign in a Norwegian newspaper. World Health Forum 1991, 12:77

52. Xu-Dubois YC, Baugey E, Peltier J, Colombat M, Ouali N, Jouanneau C, Rondeau E, Hertig A: Epithelial phenotypic changes are associated with a tubular active fibrogenic process in human renal grafts. Hum Pathol 2013, 44:1251-1261

53. Xu-Dubois YC, Galichon P, Brocheriou I, Baugey E, Morichon R, Jouanneau C, Ouali N, Rondeau E, Hertig A: Expression of the transcriptional regulator snaill in kidney transplants displaying epithelial-to-mesenchymal transition features. Nephrol Dial Transplant 2014, 29:2136-2144
54. Galichon P, Vittoz N, Xu-Dubois YC, Cornaire E, Vandermeersch S, Mesnard L, Hertig A, Rondeau E: Epithelial phenotypic changes detect cyclosporine in vivo nephrotoxicity at a reversible stage. Transplantation 2011, 92:993-998

55. Koesters R, Kaissling B, Lehir M, Picard N, Theilig F, Gebhardt R, Glick AB, Hahnel B, Hosser H, Grone HJ, Kriz W: Tubular overexpression of transforming growth factor-betal induces autophagy and fibrosis but not mesenchymal transition of renal epithelial cells. Am J Pathol 2010, 177:632-643

56. Picard N, Baum O, Vogetseder A, Kaissling B, Le Hir M: Origin of renal myofibroblasts in the model of unilateral ureter obstruction in the rat. Histochem Cell Biol 2008, 130:141-155

57. Chai Q, Krag S, Chai S, Ledet T, Wogensen L: Localisation and phenotypical characterisation of collagen-producing cells in TGF-beta 1-induced renal interstitial fibrosis. Histochem Cell Biol 2003, 119: 267-280

58. Lin SL, Kisseleva T, Brenner DA, Duffield JS: Pericytes and perivascular fibroblasts are the primary source of collagen-producing cells in obstructive fibrosis of the kidney. Am J Pathol 2008, 173: $1617-1627$

59. Pallet N, Bouvier N, Legendre C, Gilleron J, Codogno P, Beaune P, Thervet E, Anglicheau D: Autophagy protects renal tubular cells against cyclosporine toxicity. Autophagy 2008, 4:783-791

60. Kundu M, Thompson CB: Autophagy: basic principles and relevance to disease. Annu Rev Pathol 2008, 3:427-455

61. Scarlatti F, Granata R, Meijer AJ, Codogno P: Does autophagy have a license to kill mammalian cells? Cell Death Differ 2009, 16:12-20

62. Naesens M, Kuypers DR, Sarwal M: Calcineurin inhibitor nephrotoxicity. Clin J Am Soc Nephrol 2009, 4:481-508

63. Johnson DW, Saunders HJ, Johnson FJ, Huq SO, Field MJ, Pollock CA: Cyclosporin exerts a direct fibrogenic effect on human tubulointerstitial cells: roles of insulin-like growth factor I, transforming growth factor beta1, and platelet-derived growth factor. J Pharmacol Exp Ther 1999, 289:535-542

64. Fung C, Lock R, Gao S, Salas E, Debnath J: Induction of autophagy during extracellular matrix detachment promotes cell survival. Mol Biol Cell 2008, 19:797-806

65. Yang L, Besschetnova TY, Brooks CR, Shah JV, Bonventre JV: Epithelial cell cycle arrest in G2/M mediates kidney fibrosis after injury. Nat Med 2010, 16:535-543. 531p following 143

66. Grgic I, Campanholle G, Bijol V, Wang C, Sabbisetti VS, Ichimura T, Humphreys BD, Bonventre JV: Targeted proximal tubule injury triggers interstitial fibrosis and glomerulosclerosis. Kidney Int 2012, $82: 172-183$

67. Udo K, Aoki S, Uchihashi K, Kawasaki M, Matsunobu A, Tokuda Y, Ootani A, Toda S, Uozumi J: Adipose tissue explants and MDCK cells reciprocally regulate their morphogenesis in coculture. Kidney Int 2010, 78:60-68

68. Kanarek N, Horwitz E, Mayan I, Leshets M, Cojocaru G, Davis M, Tsuberi BZ, Pikarsky E, Pagano M, Ben-Neriah Y: Spermatogenesis rescue in a mouse deficient for the ubiquitin ligase $\mathrm{SCF}$ \{beta $-\operatorname{TrCP}$ by single substrate depletion. Genes Dev 2010, 24:470-477 